See discussions, stats, and author profiles for this publication at: https://www.researchgate.net/publication/340292470

\title{
Bridging Cultural Holes in Organizations: The Dynamic Structure of Social Networks and Organizational Vocabularies Within and Across Subunits
}

Article in Organization Science · March 2020

DOI: $10.1287 /$ orsc.2019.1352

CITATION

1

3 authors:

Stefano Tasselli

Rotterdam School of Management

19 PUBLICATIONS 51 CITATIONS

SEE PROFILE

Alessandro Lomi

신

172 PUBLICATIONS 2,527 CITATIONS

SEE PROFILE
READS

237

Paola Zappa

National University of Ireland, Maynooth

21 PUBLICATIONS 132 CITATIONS

SEE PROFILE

Some of the authors of this publication are also working on these related projects:

Investigating the effects of structural constraints on the relationship between repeated collaboration and performance in research-oriented teams View project

Team assembly and performance in robot-assisted surgery View project 


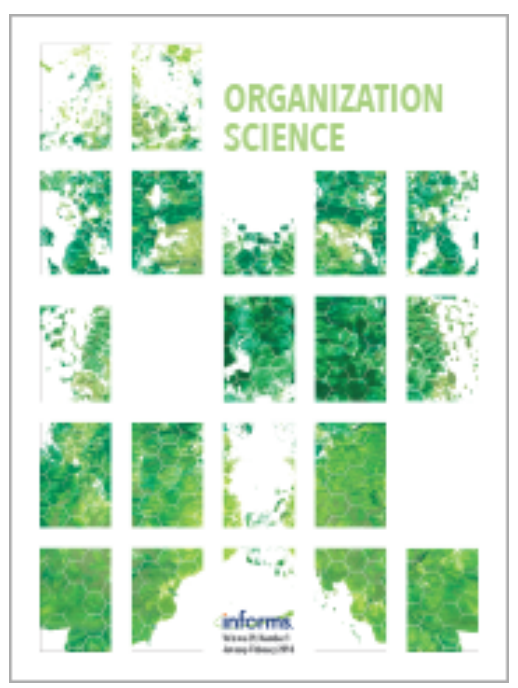

\section{Organization Science}

Publication details, including instructions for authors and subscription information: http:// pubsonline.informs. org

\section{Bridging Cultural Holes in Organizations: The Dynamic Structure of Social Networks and Organizational Vocabularies Within and Across Subunits}

Stefano Tasselli, Paola Zappa, Alessandro Lomi

\section{To cite this article:}

Stefano Tasselli, Paola Zappa, Alessandro Lomi (2020) Bridging Cultural Holes in Organizations: The Dynamic Structure of Social Networks and Organizational Vocabularies Within and Across Subunits. Organization Science

Published online in Articles in Advance 30 Mar 2020

. https:// doi. org/ 10.1287/ orsc. 2019.1352

Full terms and conditions of use: https://pubsonline.informs.org/Publications/Librarians-Portal/PubsOnLine-Terms-andConditions

This article may be used only for the purposes of research, teaching, and/or private study. Commercial use or systematic downloading (by robots or other automatic processes) is prohibited without explicit Publisher approval, unless otherwise noted. For more information, contact permissions@informs.org.

The Publisher does not warrant or guarantee the article's accuracy, completeness, merchantability, fitness for a particular purpose, or non-infringement. Descriptions of, or references to, products or publications, or inclusion of an advertisement in this article, neither constitutes nor implies a guarantee, endorsement, or support of claims made of that product, publication, or service.

Copyright (c) 2020, INFORMS

Please scroll down for article-it is on subsequent pages

\section{informs.}

With 12,500 members from nearly 90 countries, INFORMS is the largest international association of operations research (O.R.) and analytics professionals and students. INFORMS provides unique networking and learning opportunities for individual professionals, and organizations of all types and sizes, to better understand and use O.R. and analytics tools and methods to transform strategic visions and achieve better outcomes.

For more information on INFORMS, its publications, membership, or meetings visit http:// www. informs. org 


\title{
Bridging Cultural Holes in Organizations: The Dynamic Structure of Social Networks and Organizational Vocabularies Within and Across Subunits
}

\author{
Stefano Tasselli, ${ }^{\text {a }}$ Paola Zappa, ${ }^{\text {b }}$ Alessandro Lomi ${ }^{\mathrm{c}, \mathrm{d}}$ \\ ${ }^{\text {a }}$ Rotterdam School of Management, Erasmus University, 3062 PA Rotterdam, Netherlands; ${ }^{\mathbf{b}}$ School of Business, Maynooth University, \\ W23 WK26 Maynooth, Ireland; ${ }^{\mathbf{c}}$ Faculty of Economics, Università della Svizzera italiana, 6900 Lugano, Switzerland; ${ }^{\mathbf{d}}$ University of Exeter \\ Business School, Exeter EX4 4ST, United Kingdom \\ Contact: tasselli@rsm.nl, (D) https://orcid.org/0000-0002-2100-1817 (ST); paola.zappa@mu.ie, (D) https://orcid.org/0000-0002-7264-9939 (PZ); \\ alessandro.lomi@usi.ch, (iD https://orcid.org/0000-0002-2858-0022 (AL)
}

Received: December 19, 2016

Revised: December 31, 2018; October 8, 2019

Accepted: November 16, 2019

Published Online in Articles in Advance:

March 30, 2020

https://doi.org/10.1287/orsc.2019.1352

Copyright: ๑ 2020 INFORMS

\begin{abstract}
The mechanisms by which social networks and organizational vocabularies combine jointly to affect communication patterns across organizational boundaries remain largely unexplored. In this paper, we examine the mutually constitutive relation between the network ties through which organizational members communicate with each other and the vocabularies that they use to describe their organization. We suggest that the dynamic structure of social networks and organizational vocabularies is contingent on the formal design of organizational subunits. Within subunit boundaries, members who interact with each other are more likely to develop similar vocabularies over time. Interestingly, between subunits, the more two members share similar organizational vocabularies, the more likely they are to form a tie over time. We find empirical evidence for these arguments in a longitudinal study conducted among the managers of a multiunit organization. Organizational vocabularies, we suggest, may sustain communication patterns across organizational boundaries, thus bridging cultural holes within organizations.
\end{abstract}

Supplemental Material: The supplemental material is available at https://doi.org/10.1287/orsc.2019.1352.

Keywords: organizational vocabularies - organizational social networks • organizational design • boundary spanning • organizational communication

\section{Introduction}

Organizational life is made up of networks of continuously shifting relationships, and this rhythm of change calls for a deeper understanding of the theories behind the meaning of social interactions. Classic views of organizational social networks depict managers as working with proximate others, with relatively predictable tasks, and with formal separation between subunits (e.g., Ibarra and Andrews 1993). From this view, people tend to form social interactions and develop common meanings with coworkers with whom they spend most of their daily work life. These considerations, however, tend to lose their relevance in multiunit organizations in which managers can experience not only deep engagement in a group of proximate others but also ties with relatively distant others across different subunits or parts of the organization (see Burt and Merluzzi 2016). Managers' relationships, and so the meanings that they assign to their organization, increasingly squeeze organizational distance, simultaneously blending close colleagues and remote organizational subunits (e.g., Travers and Milgram 1967). Hence, the question: How do managers communicate and build social relationships within and across the social space of the organization?

Previous research has mainly provided a structural answer to this longstanding organizational question. Classic work on organizational design has given emphasis to the "structural mechanisms [that] facilitate effective coordination among differentiated yet interdependent units" (Tushman and Nadler 1978, p. 615), in order to determine "where [communication] is located that can provide the various kinds of factual premises that decisions require" (Simon 1947, p. 24). The organization itself has been described as a "caveman world," in which individuals are members of cohesive social groups, or "caves" (in the empirical setting of this paper, subunits in a multiunit organization), of strong, continuous, and redundant interactions (Watts 1999, p. 102) but in which the relatively rare ties spanning across distant subunits are also widely acknowledged as an important determinant of organizational effectiveness (Argote and Ingram 2000). More recently, studies have tried to resolve this tension by focusing on the specific relational mechanisms that may sustain the relatively 
infrequent but important boundary-crossing ties recurrently observed in actual organizations (Reagans and McEvily 2003, Caimo and Lomi 2015). This line of work builds on-and extends-the classic insight about the duality of individuals and organizational structures (Breiger 1974), implying that "when two individuals interact, they not only represent an interpersonal tie, but they also represent the groups of which they are members" (Brass et al. 2004, p. 801).

Boundary spanning in organizations, therefore, has mainly attracted structural attention to the social network mechanisms explaining cross-unit interaction (e.g., Tortoriello and Krackhardt 2010 and Tasselli and Caimo 2019). However, ties across organizational subunits also imply boundaries around "zones of meaning" (Berger and Luckmann 1966, p. 55). Social relationships, indeed, do not simply consist of sets of nodes and ties (Burt et al. 2013) but also incorporate the "individualistic coloring" (Simmel 1971, p. 257) that people provide to their social settings. Social networks are "stories" about the meaning of social structure, in which systems of meanings (White 2008) help to understand how individuals maintain and move between different social positions. In the context of organizations, the individualistic coloring that people assign to their workplace is well expressed by the concept of organizational vocabularies-that is, systems of words that individuals, dyads, and social groups use to make sense of their organizational experience (Loewenstein et al. 2012). Vocabularies provide the material basis for investigating the micromechanisms by which interacting people share structures of meanings in organizations (Lomi et al. 2017 , p. 66). The analysis of organizational vocabularies is attracting growing scholarly attention because of their novelty (e.g., Loewenstein 2014; Ocasio et al. 2015, 2018; Demetry 2017; and Painter et al. 2019) but is not yet integrated in the study of social networks and organizational functioning. However, vocabularies help to develop a better understanding of coordination patterns (Cramton 2001), cultural alignment (Basov 2019), and even friendship formation and persistence (Kovacs and Kleinbaum 2019) among organizational members, thus contributing to theoretical integration for organizational research and practice (Loewenstein et al. 2012).

Specifically, by moving beyond the structural approach to the study of intraorganizational social interaction, we investigate the dynamic structure of social networks and organizational vocabularies within and between organizational subunits (see Mische 2003 and Kirchner and Mohr 2010). The specific opportunity that we have identified in this paper concerns the two unexplored questions of (i) whether similarity between two managers in organizational vocabularies affects their likelihood to communicate with each other and (ii) whether the existence of a communication tie between two managers affects the extent to which they develop and use common organizational vocabularies. Our argument is that the dynamic structure of social networks and organizational vocabularies is contingent on the formal structure of the organization (e.g., McEvily et al. 2014). The patterns by which interpersonal interaction explains the formation of organizational vocabularies, or similarity in organizational vocabularies explains the formation of social network structure, depend on the extent to which we consider social relationships as within or between organizational subunits. We argue that within subunits, social communication patterns tend to generate over time homogeneity of vocabularies and meanings. Yet, and interestingly, sharing common vocabularies allows organizational members to span subunit boundaries and communicate across different organizational subunits.

We find empirical evidence for these arguments in a longitudinal study of communication networks and organizational vocabularies tracked for three points in time among the managers of a multinational energy organization including five distinct subunits. Our focus is on task-related communication ties among managers, given their importance for the sharing of otherwise "sticky" knowledge (Burt et al. 2013, p. 529) and for decision-making processes in multiunit organizations (e.g., Tsai 2002).

In bringing attention to the words that managers use to describe the organization and their interaction patterns, we contribute to a better understanding of the joint structure of organizational vocabularies and social networks in organizations (e.g., Groenewegen et al. 2017 and Lomi et al. 2017). Do people develop shared vocabularies because they communicate with each other in the workplace, or do they end up communicating because they share similar vocabularies? We seize upon the opportunity for integration provided by these research questions by framing organizational vocabularies and social networks as connected subcomponents of a more general meaning system within organizations. Organizational vocabularies and social networks can be recategorized as a distinctive phenomenological duality integrating "the nature of language and meaning in terms of social behaviors" with the nature of social interactions "in terms of meaning and language" (Mills 1939, p. 676). We also contribute to literature on meanings, culture, and social networks (e.g., Mische 2003) by examining the process by which interpersonal ties can bridge cultural holes in organizations (Pachucki and Breiger 2010). Similarity of vocabularies is a source of homophily crossing subunit boundaries and thus compressing organizational distance. To the extent that they help create intraorganizational bridges, organizational 
vocabularies represent a form of cultural capital that has the potential to be transformed into organizational social capital. Finally, we contribute to the growing literature on the interdependence between formal organizational boundaries and informal structure in explaining interpersonal coordination between subunits in organizations (e.g., McEvily et al. 2014).

\section{The Joint Structure of Social Networks and Organizational Vocabularies}

Defined as "systems of words and their meanings commonly used" by interacting individuals and social collectives (Loewenstein et al. 2012, p. 45), organizational vocabularies play an important role in explaining the processes by which individuals develop and share meanings in organizations (Carley 1994, Cramton 2001). For this reason, organizational vocabularies help provide common grounds that facilitate the understanding of coordination within and across organizational boundaries (Lomi et al. 2017, p. 66). Organizational boundaries, indeed, do not have agency onto themselves if separated from fundamental cultural processes by which individuals assign meaning to the organization (Pachucki and Breiger 2010). Formal boundaries within and around organizational subunits identify discursive entities or "zones of meaning that are linguistically circumscribed" (Berger and Luckmann 1966, p. 55). Thus, membership of organizational subunits, and the ties spanning across such subunits, entail the absorption and construction of systems of meanings that individuals develop to make sense of the social space of the organization.

Classic and more recent research has investigated the role of vocabularies in the social construction of organizational structure (e.g., Berger and Luckmann 1966 and Oberg et al. 2017). By "expressing communal values, evoking past experiences, providing seed beds for human action," vocabularies represent "a vehicle for achieving practical effects" (Pettigrew 1979, p. 575) that may affect patterns of organizational action and interaction (Lockwood et al. 2019). Sharing vocabularies within and across social settings helps coordination between interacting individuals (Bechky 2003). Language matching can help explain the extent to which people interact in dyads (e.g., Shi et al. 2019), cluster together in cohesive groups, and assign common meanings to the settings to which they belong (Carley 1986).

Despite this increased interest in vocabularies within and across organizations, the study of vocabularies has been traditionally "substantially unexplored" in relation to the study of organizational social networks (Lomi et al. 2017, p. 69). As noticed by Loewenstein et al. (2012, p. 37), "Language use pervades organizational life, but its promise has remained elusive." Organizational vocabularies feature social interactions as embedded in local microcultures (Collins 2003), which are made resonant by the formal subunit boundaries defined by the organizational structure. Yet we do not know whether shared organizational vocabularies explain processes of tie formation between interacting individuals in organizations or whether the presence of social ties between organizational members explains the likelihood that such members will develop similar vocabularies.

We answer these questions by integrating two key theoretical approaches to organizational vocabularies from the social sciences (Loewenstein and Ocasio 2005) with research on organizational social networks. On the one hand, the approach first developed by Mills $(1939,1940)$ suggests that social and organizational structure can influence the use that people and social collectives make of organizational vocabularies, by exerting consequences on the structure of thoughts. From this perspective, communication shapes the interindividual formation and use of vocabularies, such that "thinking follows the pattern of conversation" (Mills 1939, p. 673). Specifically, Mills envisages prospects for an organizational view of vocabularies of structure, building on the consideration that "thought [and thus language] is not an interaction as between two impenetrable atoms; it is conversational and dynamic" (Mills 1939, p. 673). Consequently, interpersonal networks can model the structure of organizational vocabularies, an intuition well captured by the evidence that when an organizational member communicates with others, "he is not trying to describe his experienced social action. He is not merely stating 'reasons.' He is influencing others-and himself" (Mills 1940, p. 907).

On the contrary, neo-Whorfian approaches based on linguistic relativism emphasize the extent to which language and thus vocabularies influence categories of thought and shape, in turn, patterns of social action and interaction (e.g., Gentner and Goldin-Meadow 2003). From this perspective, language provides the common ground for basic categories of cultural similarity and variation upon which social ties are forged. Different from the focus of Mills on vocabularies of structure, linguistic relativistic approaches privilege a focus on vocabularies as structuring the organization, such that patterns of cultural and meaning alignment in the use that people make of vocabularies constitute the phenomenological premise behind patterns of interpersonal interaction. Because "every word in a vocabulary of organizing constitutes a category of organizing activity," organizational vocabularies can "provide organizational members with specific categories" with which to think, act, and interact (Loewenstein and Ocasio 2005, p. 9).

In this paper, we bridge these competing approaches to language and structure with social network theory 
to study the dynamic interplay of social networks and vocabularies in organizations as contingent on the design of the formal organizational structure. We combine the social influence perspective on vocabularies introduced by Mills (1939) with the social network argument that close and proximate interactions incentivize cohesion and homogeneity (e.g., Tortoriello et al. 2012) to hypothesize that social interactions contribute to shape organizational vocabularies within organizational subunits (Hypothesis 1). And we build on the linguistic relativistic argument that language can influence social action and interaction (see Bowerman and Choi 2001) to introduce the concept of meaningful bridging ties crossing organizational distance; specifically, we hypothesize and test that sharing common vocabularies affects tie formation while looking at interactions between organizational subunits (Hypothesis 2). In our view, the idiosyncratic nature of organizations emerges from the interplay between their formal and informal structure (in terms of formal subunits and of informal ties among members) and patterns of similarity and difference in the vocabularies that members assign to the organization.

\section{Ties Within Subunits Influence the Development of Common Organizational Vocabularies}

Communication ties between managers within organizational subunits play a central role in enabling organizational functioning and coordination. Proximate ties with subunit comembers provide social platforms that facilitate interpersonal coordination (Hinds et al. 2000) and help the inclusion of new members in the organization (Morrison 2002). For these reasons, withinsubunit ties enable the generation of specialized knowledge that reflects the nature of each subunit's tasks or activities (Uzzi 1999). Through repeated interaction and development of localized knowledge, indeed, ties within subunits entail the absorption and construction of systems of meanings that individuals develop and share to make sense of the social environment in which they live and work (Weick et al. 2005).

From a social network perspective, this classic view of organizational subunits as separated social arenas in which individuals organize and coordinate activities (Homans 1950) reflects the presence of local, cohesive network structures that exhibit a group-like identity and promote the development of shared norms and expectations (Krackhardt 1999). Specifically, interaction in localized networks tends to constrain people's individuality (Tasselli and Kilduff 2018), favoring interpersonal coordination (Tortoriello et al. 2014), promoting knowledge sharing (Tasselli 2015), and enabling the formation of "super strong and sticky" connections (Krackhardt 1998). The prevalence of socially enforced group culture typical of organizational subunits urges interacting individuals in local networks to develop shared languages that reflect group norms, common values, and meanings (e.g., Lomi et al. (2014)), obedience to which is monitored by group members (Kilduff et al. 2006). Interaction within organizational subunits provides the "circumscribed social coordinates," which, according to Mills (1939, p. 678), are needed to test the influence of structure on language.

Building on these arguments, our first, baseline hypothesis is that the ties formed by members of the same organizational subunit may induce local bonds that activate, and reinforce, the effects of social interaction on the development of shared organizational vocabularies and related meanings that people assign to their organizational settings. Subunit membership offers the homogeneous repertoire of shared professional knowledge (Abbott 1988), experiences (Marsden 1988), and localized perceptions and memories (Tasselli 2019) upon which common language may be forged. By interacting with subunit comembers, specifically, people activate processes of shared vocabulary formation, thus reinforcing within-group interaction as distinguished from interaction with others in organizational out-groups (Ashforth et al. 2011). According to Loewenstein et al. (2012, p. 35), organizational vocabularies are "generators of meanings within social collectives." Therefore, we expect that managers interacting in the same organizational subunits will tend to adopt over time similar vocabularies to describe their organization.

Hypothesis 1. Within organizational subunits, two members who entertain a task-related communication tie are more likely than members who do not communicate with each other to increase similarity in organizational vocabularies over time.

\section{Sharing Similar Organizational Vocabularies Influences Tie Formation Across Subunits}

The image of the organizational network implied by the first hypothesis is consistent with that of the above-mentioned caveman world, in which members develop similar languages because they interact with each other within organizational subunits (or organizational caves, paraphrasing Watts 1999). Meaningful caves, we argue, but caves nonetheless. However, organizations are rarely decomposable into fragmented caves: the formal boundaries of organizational subunits might contain the majority but, typically, not all of the observed ties among their members (e.g., Caimo and Lomi 2015). So what makes these "distant" ties bridging organizational subunits possible?

The answer provided by research on organizational design emphasizes the functional relevance of interdependences between purpose-built organizational subunits (Thompson 1967). The fragmentation 
of knowledge inherent in the successful implementation of organizational design solutions makes particularly valuable the difficult task of integrating heterogeneous resources across organizational boundaries (Tortoriello and Krackhardt 2010). Because of their integrating role, ties spanning across subunits facilitate processes of problem solving and knowledge recombination (Argote et al. 2003). Individuals tend to form boundary-spanning ties to coordinate tasks and activities across otherwise disconnected parts of the organization (Tasselli and Caimo 2019).

This structural emphasis has fueled an increasing amount of research investigating the patterns by which ties with relatively distant others can inhibit and facilitate the outcomes not just of individuals but also of communities and organizations (e.g., Ryan 2016). Structural arguments, however, do not take into adequate account evidence that individuals in organizations are recipients of social and cultural influence (Srivastava and Banaji 2011, Chua 2018). Serendipitous encounters with distant others, including members of distinct organizational subunits, can be made meaningful by the homophilous embeddedness of each person in cultural networks (Pachucki and Breiger 2010, Basov 2019), in which even distant people share common values, beliefs, or meanings.

Far from considering bridging ties as purely structural, we argue that they can also be meaningful. The meanings that people assign to the organization through vocabularies can activate homophilous patterns bridging across organizational distance. In the context of ties across subunits, in particular, what can make these distant encounters meaningful —and then activate processes of tie formation-is the presence of vocabulary homogeneity between members of different subunits. Extensive experimental evidence showed that similarity in culture, meanings, and values leads to attraction and interaction (McPherson at al. 2001), such that the presence of shared meanings between members of different social groups is associated with enhanced likelihood to connect (e.g., Sherif 1958). Similarity in meanings and even in the affective value that people assign to the organization can explain the extent to which people form task-related ties beyond the formal-structural requirements of organizational coordination and functioning (Casciaro and Lobo 2014). The presence of shared organizational vocabularies among members may capture this source of homophily: vocabularies are a relatively visible discursive entity-that is, "socially constructed sets of linguistic categories used ... both to make sense of organizational reality and to bring attention to available sources of organizing activities" (Ocasio and Joseph 2005, p. 165). By sharing words and even gossip concerning the organization, relatively distant individuals belonging to different subunits reduce information asymmetry and build a confidential, value-based background upon which meaningful ties are forged (e.g., Burt 2008). Sharing organizational vocabularies might reduce the perceived cost of interacting with relatively unknown others across the social space of the organization (Duncan et al. 1968). By using similar vocabularies, indeed, organizational members develop and share common meanings that help define and make sense of the overall organization (Loewenstein et al. 2012). The vocabularies that they use to describe their organization influence, in turn, their ability to think about the organization and, subsequent to these thoughts, to interact with coworkers who share the same vocabulary (Gartner 1993).

We hypothesize, therefore, that sharing similar vocabularies activates processes of tie formation between members of different organizational subunits. Formal organizational boundaries are resonant in organizations because they involve systems of words and meanings by which professionals make sense of the social space in which they exert their activities (Maitlis and Christianson 2014). Through the process by which similarity in organizational vocabularies triggers social interaction across boundaries, we suggest that organizational members contribute to bridge the "cultural holes" that make coordination across the social space of the organization both difficult and necessary (Pachucki and Breiger 2010). Thus, we introduce our second hypothesis. The description of the mechanisms leading to the two hypotheses is shown in Figure 1.

Hypothesis 2. Between organizational subunits, the more two members share similar organizational vocabularies, the more they are likely to form a task-related communication tie over time.

\section{Data and Methods Empirical Setting}

We examine the dynamic links between managers' social networks and organizational vocabularies in the context of task-related communication relations aimed at decision making among the managers of the multiunit regional branch (hereafter referred to simply as the organization) of a multinational energy and services group. The organization contains five quasiindependent subunits (hereafter referred to as subunits) involved in the development and selling of businesses and communities energy solutions and services. Each of the five subunits covers core business activities of the organization: natural gas; renewable energies; energy services to households and business; logistics and mobility; and spaces, buildings, and facility management. In addition, the organization includes an administrative department that was not included in this study because it was outside the core 
Figure 1. The Dynamic Structure of Communication Ties and Organizational Vocabularies

(a)

Communication ties within subunits explain increase in vocabulary similarity between managers over time.

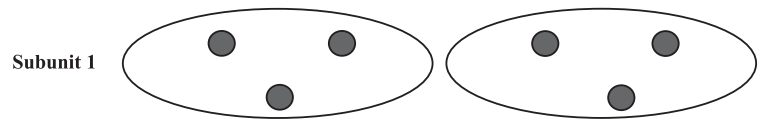

Subunit 2

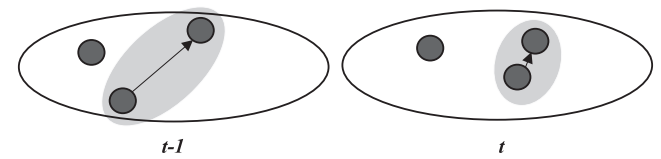

(b)

Vocabulary similarity between managers belonging to different subunits explains communication tie formation over time.

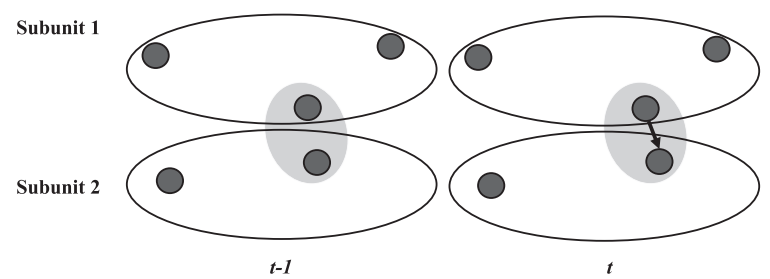

Notes. White ovals are subunits. Dark grey dots are managers; black arrows are task-related communication ties. The closer two dots are in the space, the more similar their organizational vocabularies are. In panel (a), the grey oval encircles the dyad that verifies Hypothesis 1; in panel (b), the grey oval encircles the dyad that verifies Hypothesis 2.

range of strategic activities of the organization. The subunits are quasi-independent because they are integral parts of the organization, but they are present in different ranges of activities in the industry, they have different suppliers and customers networks, and (more important, for our purposes) they have independent managers.

The opportunity to collect empirical data in this context was triggered by the fact that the global management asked the organization to start a process to rethink its goals, activities, and key indicators. For this purpose, the organization had to develop and discuss in approximately four months the "expected ambitions, tasks and evolutions" for the upcoming years. This represented a window of opportunity for both a reshuffle of social network ties among managers (see Sasovova et al. 2010) and the development of their organizational vocabularies (e.g., Vaara et al. 2016). Indeed, managers had increased chances to reflect on the core activities and values of the organization and to interact with each other during the observed period, including days of presentations and discussion, and opportunities for informal coordination within and across subunits.

The global management of the group identified organizational members (the "managers") they would consider the most relevant decision makers in the five subunits of the organization. After the careful work of selection, they identified a target number of 47 members who were working in the company and were recognized as the management team of the organization. Forty managers completed the entire data collection ( $85 \%$ of the target sample). There was no statistical difference between respondents and nonrespondents on gender, nationality, and tenure. The list of respondents included subunits' managers, as well as each subunit's director, the chief financial officer (CFO) (formally assigned to the service subunit), and the chief operating officer (COO) (member of the facility management subunit) of the organization. Of the 40 managers, 8 were assigned to the natural gas subunit (average tenure $=8.5$ years, $S D=$ 3.07), 7 to the renewable energies subunit (average tenure $=10.71$ years, SD $=4.03$ ), 7 to the energy services subunit (average tenure $=10.14$ years, $S D=$ 2.79), 6 to the logistics and mobility subunit (average tenure $=11$ years, $S D=5.06)$, and 12 managers to the facility management subunit (average tenure $=9.83$ years, SD = 3.74). During the entire period of data collection, no manager moved from one subunit to another.

\section{Data Collection}

Social Networks. We collected information on social networks among the managers using the roster method, an approach commonly used in organizational social network research (e.g., Mehra et al. 2001, Sasovova et al. 2010, and Carnabuci and Diószegi 2015), which is particularly appropriate for gathering network data on bonded organizational settings (e.g., Tasselli and Kilduff 2018) and reduces the likelihood that respondents forget important contacts (Wasserman and Faust 1994). Repeated network data collections over time using the roster method reduce the "potential for survey response bias" that may be associated with onepoint collection (Reagans 2011, p. 840). Data were collected at three points in time in a four-month interval, the first one at the beginning of the process of redesign (hereafter referred to as time 1), the second one approximately two months later (time 2), and the third one approximately four months later (time 3). Each respondent was asked to report the presence of a relation of task-related communication aimed at decisionmaking purposes regarding day-to-day activities with each of the other members of the management team. Respondents confronted the following task:

It is not unusual to communicate with colleagues about work-related tasks aimed at decision making purposes. In this section of the questionnaire, we are interested in obtaining information about colleagues with whom you communicate about work-related tasks aimed at decision-making purposes in the last two weeks. Please indicate your answer by placing a check next to the names of those colleagues with whom you typically exchange work-related communication 
aimed at decision-making. If there is only one person you might communicate with, then just check that one person's name. If there are several people you might communicate with, then check these several names. If there is no one you communicate with, then do not check any name.

The task of reconstructing the personal communication networks was specified further and made more contextually relevant by asking respondents to think about "communication about tasks that you believe your contacts may consider useful for making decisions concerning the organization, but to which they may not have direct access," and "communication to let your contacts know about tasks that you might consider useful, but to which you do not have direct access." The outcome of each of the three roster questionnaires collected at three points in time was a binary adjacency matrix of size $40 \times 40$, representing work-related communication among the managers. Respondents provided a total of 190 contacts at time 1 (on average, 4.75 contacts per person), 304 at time 2 (7.60 contacts per person), and 239 (5.98 ties per person) at time 3 . In more detail, within subunits, managers had, on average, 2.95 ties at time 1, 3.33 ties at time 2 , and 2 ties at time 3 . Between subunits, the average number of ties for each manager was 1.80 at time $1,4.27$ at time 2 , and 3.98 at time 3 .

Organizational Vocabularies. Studies on vocabularies can focus on tracing the use of specific words or all words in a corpus of texts (Loewenstein and Ocasio 2005). We chose to adopt the latter approach, because it allows analyzing the full complexity and richness of the vocabularies used by the managers (Abrahamson and Hambrick 1997). Therefore, we did not select a priori keywords that we deemed relevant to the examined managers but let all the keywords emerge from the analysis (Weber 1990). To reconstruct the social structure of organizational vocabularies, which is the conceptual core of this paper, we focused on the association between managers and the interrelated set of keywords describing their organization (e.g., Hirsch 1986 and Jones and Livne-Tarandach 2008). Specifically, we asked each respondent to write a short text (maximum of 500 words) describing "your experience and understanding" of the organization, "including its characteristics, values and beliefs" (Balogun and Johnson 2004, Sonenshein and Dholakia 2012). Compared with studies of organizational vocabularies using secondary data (e.g., company reports; Jones and Livne-Tarandach 2008), primary data collection of texts written by organizational respondents allows analyzing more comprehensively the emergence of "organizationally relevant" keywords that inform contextual processes of interpersonal collaboration and decision making (Vaara et al. 2016).
Each respondent completed the same task at three different points in time, simultaneous to the social network data collection.

Overall, we gathered during the three waves of data collection a corpus of 120 texts, whose length is an average of 184.4 words per person at time 1 (ranging from a minimum number of 54 words to a maximum of 380 words per person), 219.6 words per respondent at time 2 (ranging from 82 to 369 words per respondent), and 163 at time 3 (with a minimum of 27 and a maximum of 339 words). This length is comparable with previous research examining texts collected through open-ended questions (e.g., Carley 1997). Examples of sentences written by respondents include the following:

We take the major challenges of the energy transition towards a low-carbon economy: Access to a sustainable economy, attenuation of and adaptation to climate change, security of supplies and optimized use of resources.

The end goal is the ability to reach innovation through valued activities and excellence through collaboration and the generation of constructive consensus. One voice from different voices, one value proposition from the contribution of different people and different subunits, one optimal goal through the sum and the result oriented integration of multiple individual and collective goals. One organization for a modern, people-oriented energy group.

In addition, we conducted interviews with key informants (managers responsible for innovation and engineering services) to validate and make sense of the texts written by the respondents. The qualitative data of these interviews are not included in the present study but helped provide the research team with a better overview of the core activities of the organization.

Analysis of Organizational Vocabularies. We analyzed the texts adopting a quantitative approach (e.g., Loewenstein et al. 2012). The process of extracting the keywords and reconstructing the organizational vocabulary of each manager consisted of a multistep procedure (e.g., Jones et al. 2012). First, from the initial list of 1,289 distinct words provided by the managers, we cleaned the texts filtering out noninformative words, which include articles, conjunctives, and pronouns; we retained informative words, such as adjectives, nouns, and verbs. Second, to enhance comparability between texts, we investigated common semantic patterns for the words used by respondents by bringing back semantically similar words to their common semantic root and reducing keywords to their common stem (e.g., Jones and Livne-Tarandach 2008). Thus, words such as "industry," "industries," "industrial," and "industrially" were recoded as "industr-"; words 
such as "adverse" and "adversity" as "advers-"; and so on. Third, we generalized concepts that have a similar meaning in our context. Specifically, we used semantic dictionaries (i.e., the American Heritage Dictionary and the Oxford English Dictionary) to identify synonyms, which we combined into common concepts. For example, the words "company," "firm," and "organization" were simply replaced by the common concept of "organiz-" - the most common variant among the three. This allowed generalizing into conceptually common categories words that would otherwise be excessively context dependent (e.g., specialized jargon), that are idiosyncratic to specific respondents, or that would fragment common or synonymous concepts into an excessive number of different keywords (e.g., Krippendorff 2004). Being aware of the potential risks and limitations inherent in this procedure, including concept vagueness and loss of relevant semantic distinctions (e.g., Mohr et al. 2013), we manually checked the texts for all possibly ambiguous cases to ensure that words that can have multiple meanings were not assigned to the wrong concept. From this procedure, we obtained a list of 242 distinct words, 211 from the first period, 238 from the second, and 221 from the third, which indicates that most words were present in all periods. ${ }^{1}$

For each of the three periods, we then arranged each list of words into a "text by word" matrix sized $(n \times m)$, where $n$ is the number of respondents (40 in each period) and $m$ the number of words (211 at time 1, 238 at time 2 , and 221 at time 3 ). The generic entry $f_{i k}$ of each matrix is the raw frequency count of each word $(k)$ used by respondents in each text (i) written by respondents. We acknowledge that raw frequency counts do not accurately map the relative importance of a word in a given text, because variance in text length and word usage across texts cannot be adequately accounted for (Jones and Livne-Tarandach 2008). To avoid this issue, we transformed the raw frequencies through the term frequency-inverse document frequency technique. This technique allows a more accurate and reliable representation of a word relevance in each manager's vocabulary by correcting the raw frequencies for the text length and a weighting factor that accounts for the number of texts containing the word ${ }^{2}$ (e.g., Carley et al. 2012).

\section{Dependent Variables}

On the basis of its conceptual design, the study includes two distinct dependent variables: Vocabulary similarity change, testing the first hypothesis, and Interpersonal tie change, testing the second hypothesis. Because we collected repeated observations of the same variables over time, we arranged the data into a panel.
Vocabulary Similarity Change. To assess empirically the extent to which people use more or less similar vocabularies over time, we first retained only the most frequently occurring words in the texts in order to enhance comparability (Nag et al. 2007). We set a minimum frequency threshold and retained $80 \%$ of the original word observations in each period, corresponding to keeping words used by at least seven managers in each period (e.g., Nag et al. 2007 and Dunn and Jones 2010). This resulted in a list of 84 words at time $1(2,790$ observations out of the initial $3,494), 97$ words at time 2 (3,221 observations), and 83 words at time 3 (2,452 observations). This ratio has been proven to preserve the structure of the original vocabulary and ensure robust results of text analysis (e.g., Weber 1990). The highest-frequency words were "country," "energy_source," "facility," "nature," and "service," each of them appearing at least 104 times in the managers' texts across the three periods (see the complete list of words in Appendix $\mathrm{A}$ in the supplemental material). We conducted sensitivity analysis with alternative thresholds $(60 \%$, $70 \%$, and $90 \%$ of the raw number of observations), and results were unchanged.

Then, we applied correspondence analysis - one of the most widely used methods for mapping out and measuring the relational systems of differences in the use of vocabularies (Breiger 2000, Breiger and Mohr 2004). Intuitively, correspondence analysis allows identifying classes of similar words and classes of similar texts (in our setting, the texts written by each manager) by examining the rectangular text by word matrix and detecting a significant association between its rows and columns (i.e., managers and words). The method works inductively and computes the $\chi^{2}$ distance between words and managers in the matrix based on their patterns of co-occurrence. Matrix algebra (specifically, singular value decomposition) is then applied to compute factors (technically, coordinates) for managers and words (Greenacre and Blasius 1994). Compared with other approaches assessing vocabulary similarity by accounting for the simple presence of overlapping words, this approach captures the use of more and less important co-occurring sets of words, and therefore it better reflects similarity at the level of the vocabulary as a whole as well as revealing the existence of shared topics.

We analyzed the outcome of correspondence analysis in two steps. First, we examined the association between words and between managers and the words they use in the texts. The output of this mainly descriptive step is to depict the two principal coordinates for words and managers onto a map (e.g., Breiger and Mohr 2004 and Crilly and Sloan 2014). (The three maps are included and described in Appendix B in the supplemental material.) Then, we used coordinates 
for managers to compute an index of similarity of the vocabularies that they adopted. Following standard practice (e.g., Meyer and Höllerer 2010), we decided to retain as many coordinates as those capturing around $90 \%$ of the variance in the related text by word matrix. This resulted in retaining the first eight (principal) coordinates for each manager. We used the coordinates to compute the Euclidean distance between manager $i$ and manager $j$. Then, we normalized the distance and subtracted it from 1 to obtain vocabulary proximity or similarity. ${ }^{3}$ Vocabulary similarity values range between 0 and 1 . The higher the values, the more similar the vocabularies adopted by pairs of managers - that is, managers share many or all words used to describe the organization. Finally, we created Vocabulary similarity change, the first dependent variable, by computing for each dyad $(i, j)$ the difference between the similarity value at $(t)$ and at $(t-1)$. In doing so, we captured increases and decreases in the similarity level over time.

Interpersonal Tie Change. Wenext measured the extent to which individuals form ties over time. From each of the three networks, we extracted all possible pairs of managers $(i, j)$ and built a binary dyadic variable, Interpersonal tie. For each manager $i$ and $j$ in the data set, the binary variable takes a value of 1 if $i$ has a taskrelated communication tie with $j$ at time $(t)$ and 0 if not. For each dyad $(i, j)$, we then compared the value of the binary variable at times $(t-1)$ and $(t)$. We codified Interpersonal tie change as 1 if manager $i$ forms a new tie with manager $j$ between $(t-1)$ and $(t)$ and 0 if they do not (e.g., Kleinbaum et al. 2015). This binary coding of the dependent variable distinguishes between new ties formed at $(t)$ and all other ties (i.e., nonformed, maintained, dissolved) only. To provide an alternative assessment of tie change, in additional analysis we codified the dependent variable as 2 if a new tie was formed between manager $i$ and $j, 1$ if an existing tie was maintained, -1 if it was dissolved, and 0 (the baseline outcome) if the tie did not exist in either period. When testing the models with this alternative specification, patterns of results remained unchanged.

\section{Independent Variables}

Our conceptual design focuses on testing whether task-related communication shapes the evolution of organizational vocabulary similarity within subunits (Hypothesis 1) and whether organizational vocabulary similarity shapes the evolution of task-related communication between subunits (Hypothesis 2). This implies that the independent variables mirror the dependent ones and requires that the two hypotheses are tested in separate models.

To test Hypothesis 1, we computed as the independent variable Interpersonal tie $(t-1)$. As discussed in the previous subsection, this variable equals 1 if manager $i$ entertains a task-related relationship with manager $j$ at time $(t-1)$ and 0 otherwise. Then we computed Same subunit. This is a binary variable that equals 1 if two managers are members in the same subunit and 0 otherwise. The interaction between Interpersonal tie $(t-1) \times$ Same subunit tests Hypothesis 1 .

To test Hypothesis 2, we computed the second independent variable, Vocabulary similarity $(t-1)$, capturing the degree of similarity between manager $i$ and $j$ at $(t-1)$. Then we specified Different subunit. This is a binary variable that equals 1 if two managers are members in different subunits and 0 otherwise. The interaction Vocabulary similarity $(t-1) \times$ Different subunit tests Hypothesis 2.

\section{Control Variables}

Because similarity is a basic organizing principle for social relations (O'Reilly et al. 1989, Hinds et al. 2000, McPherson et al. 2001), sharing relevant demographic or organizational attributes may affect the experience that individuals accumulate, increasing the propensity to communicate (Ibarra 1999) as well as to develop similar patterns in the adopted organizational vocabularies. We controlled for Same gender and Same nationality as dichotomous variables, which equal 1 if two managers share the same value of the variable and 0 otherwise (Reagans and McEvily 2003). Men made up $82.5 \%$ of the sample, and $40 \%$ were citizens of the home country of the organization.

With respect to work-related attributes, we controlled for previous subunit, educational background, role, and tenure, all dimensions that have been found to exert an influence on interaction patterns (Gulati and Puranam 2009), specialist knowledge and meanings (Strong and Robinson 1990), and the propensity to communicate (Tasselli 2015). First, because the possibility of managers' rotation across subunits may influence social interaction (e.g., Lomi et al. 2014), we checked for whether managers were members of the same or of a different subunit in the two years before data collection. Specifically, we defined Same previous subunit as a dummy variable equal to 1 if two managers were previously members of the same subunit and 0 otherwise. Second, we controlled for educational background as the type of academic title obtained (technical versus managerial degree), measuring Same background as a dichotomous variable that takes a value of 1 if two managers possess the same type of degree and 0 if they do not. Organizational role was measured as a dichotomous variable differentiating managers in a higher hierarchical position (i.e., subunit head, $\mathrm{CFO}$, and $\mathrm{COO}$ ) from other managers, and we used it to build Same role, a dummy variable that takes a value of 1 if the respondent and the contact have the same organizational role and 0 otherwise. 
Finally, Tenure dissimilarity was computed as the (absolute) difference in the number of years spent in the organization between a respondent and a contact.

Individuals can also be more likely to communicate with others (e.g., Dokko et al. 2014) and develop a similar system of meanings (e.g., Carley 1994 and Jones et al. 2012) because they identify with their subunit or with the superordinate organization. Social identity is defined as an individual's "knowledge that he [or she] belongs to certain social groups together with some emotional and value significance to him [or her] of that group membership" (Tajfel 1972, p. 292). We measured Subunit identity and Organization identity using the visual scale developed by Bergami and Bagozzi (2000; see also Lomi et al. 2014), which assesses the overlap between selfperceived identity and the perceived identity of the organization ranging from 1 (manager and subunit identities are far apart) to 8 (self- and organizational identities completely overlap). We repeated the analysis controlling for subunit and organizational identity at the dyadic level, measured as Subunit and Organization identity dissimilarity, respectively. Results remained unchanged.

Finally, we controlled for structural features of the communication network, including network size, reciprocity, and structural equivalence. A respondent's overall Network size accounts for the logged number of contacts in the communication network of each manager at $(t-1)$ (e.g., Dokko et al. 2014). We obtained the same results when including in the models Network size dissimilarity $(t-1)$ between the respondent and the respondent's contacts. Reciprocity captures the extent to which social interactions are symmetrical and might affect communication patterns and meaning formation (e.g., Kleinbaum et al. 2015). It was measured computing for each relationship between two managers $i$ and $j$ not only the "tie sent" but also the "tie received," such that the relationship $R_{i j}=1$ if both $i$ goes to $j$ and $j$ goes to $i$; otherwise, $R_{i j}=0$ (see Kleinbaum et al. 2015). Finally, structural equivalence measures the extent to which two managers are involved in the same patterns of relationships (i.e., interact with the same colleagues) (Burt 1987). We assessed the degree of Structural nonequivalence between managers $i$ and $j$ as the Euclidean distance between the network pattern surrounding the former and the network pattern surrounding the latter at time $(t-1)$ (Reagans and McEvily 2003).

\section{Empirical Model Specification and Estimation}

Because we are interested in investigating the determinants of communication ties and vocabulary similarity between pairs of managers, our data set is dyadic-that is, observations are of type $(i, j)$.
Consistent with our longitudinal hypotheses, the dyads are repeated in time. Overall, the data set consists of 4,680 dyads involving the 40 managers across the three periods. It follows that there can be multiple observations for each respondent and each contact within and across periods. This may potentially violate the key assumption of independent observations in standard regression. Error terms in the regression could be correlated across observations from the same focal actor or contact. Without accounting for this nonindependence, the standard errors of the estimates can be deflated artificially, and the model could appear to fit better than it actually does. This issue is typically addressed by estimating a random-intercept model, where a fixed effect is introduced for each pair of actors (e.g., Reagans 2011). We created a dummy variable for each manager in the sample. Within a particular dyad, the dummy variables for the focal actor and the contact were set equal to 1 , and all other dummy variables were set equal to 0 . The fixed effects estimation also allows controlling for any unobserved heterogeneity among respondents (Mizruchi and Koenig 1988). In addition, we included time dummies to control for time-specific unobserved heterogeneity. In supplemental analysis (not included in the main tables but available upon request), we controlled also for unobserved heterogeneity at the subunit level by including subunit dummies.

Because one dependent variable (Interpersonal tie change) is binary and the other (Vocabulary similarity change) is continuous, we had to run different regression models to test our two hypotheses. Models testing the first hypothesis, and regressing Vocabulary similarity change between $(t-1)$ and $(t)$ on Interpersonal tie $(t-1)$, were specified as linear regression models and estimated with the least square method. The change in the degree of similarity of the organizational vocabulary adopted by each dyad $(i, j)$ was modeled as a function of the existence of a tie at $(t-1)$, its interaction with the subunit affiliation, time-varying control covariates (all lagged by one period), and time-invariant ones. As an additional control, we included the lagged dependent variable (e.g., Khaire 2010), Vocabulary similarity $(t-1)$. Because Interpersonal tie change is a binary variable, we specified a logistic regression model to test the second hypothesis. The logit specification modeled the logarithm of the odds of the tie formation within each dyad $(i, j)$ at time $(t)$ as a function of the similarity in the organizational vocabulary at $(t-1)$ and its interaction with the subunit affiliation and the control variables (see also Kleinbaum et al. 2015). In each model, $(t-1)$ indicates the period before the observation period $(t)$ considered in the analysis. This model specification with lagged variables allowed 
alleviating endogeneity issues (Wooldridge 2009). To include the variables in the models, we adopted a stepwise procedure. Also, we did not find any multicollinearity between variables (variance inflation factors values were lower than 3.80). As is standard procedure in the case of fixed effects regression, we considered as an alternative approach pooled estimation, obtaining the same patterns of results.

\section{Results}

Table 1 displays descriptive statistics and correlations for the panel data. The dyadic data set includes 4,485 observations; 195 observations were dropped because of missing values in the identity-related variables. Interpersonal tie was measured as a dichotomous variable capturing the existence of a tie between pairs of managers and presented an average value of 0.16 $(\mathrm{SD}=0.37)$, indicating that $16 \%$ of all possible ties actually exist across the observation period. The average value of Interpersonal tie change was $0.04(\mathrm{SD}=$ 0.20 ), with 135 new ties created during the observation period. Vocabulary similarity between pairs of managers was measured on a scale from 0 to 1 and exhibited a fairly high average value during the entire observation period $(M=0.57, \mathrm{SD}=0.22$, with a minimum value of 0 and maximum value of 0.99 ). More specifically, Vocabulary similarity increased during the observation period, with an average value of 0.46 at time 1, 0.61 at time 2, and 0.63 at time 3 . As expected, the average degree of vocabulary similarity within subunits (0.72) was higher than between subunits (0.53) across the entire observation period. Changes in vocabulary similarity were, on average, moderate but highly heterogeneous $(M=0.07, \mathrm{SD}=$ 0.20 , with a minimum value of -0.78 and maximum value of 0.82 in the sample). Vocabulary similarity change and Interpersonal tie change- the two variables of conceptual interest in this study-were almost independent $(r=-0.02)$.

Table 2 presents results of linear regression models testing the effects of communication ties observed at period $(t-1)$ on the vocabulary similarity at period $(t)$. Recall Hypothesis 1: within organizational subunits, two members who entertain a task-related communication tie are more likely than members who do not interact with each other to increase similarity in vocabularies over time. This hypothesis was supported. As shown in Model 5, the interaction of Interpersonal tie $\times$ Same subunit is positive and significant $(\mathrm{B}=0.107$, $p<0.01)$ and improves the explained variance by $1 \%$ (adjusted $R^{2}=0.49$ ) compared with Model 4, where controls and independent variables were tested. The $F$-test confirmed that the improved variance explained by the adjusted $R^{2}$ is statistically significant. Consistent with our prediction, just entertaining a tie with a coworker in the organizational network does not explain the likelihood to develop a similar vocabulary with that coworker over time $(B=0.006, p=0.61)$. Membership of the same subunit makes resonant the effects of taskrelated communication ties on vocabulary similarity.

To probe the interaction effect of Interpersonal tie $x$ Same subunit on Vocabulary similarity change, we plotted the marginal effects for the nonexistence versus existence of a tie by subunit affiliation (Aiken and West 1991), setting all other covariates to their mean values (because both variables are binary, two $y$-values only are observed for each value of subunit affiliation). Figure 2 displays the margins, showing that, within subunit boundaries, managers interacting with each other are more likely to increase similarity in their organizational vocabularies over time than managers who do not interact. A simple $t$-test showed that for managers who are members of the same subunit, the existence of a task-related tie

Table 1. Descriptive Statistics and Correlations

\begin{tabular}{|c|c|c|c|c|c|c|c|c|c|c|c|c|c|c|c|}
\hline & Mean & SD & (1) & $(2)$ & (3) & (4) & (5) & (6) & (7) & (8) & (9) & $(10)$ & (11) & $(12)$ & (13) \\
\hline DV: Interpersonal tie change & 0.04 & 0.20 & & & & & & & & & & & & & \\
\hline DV: Vocabulary similarity change & 0.07 & 0.20 & & & & & & & & & & & & & \\
\hline (1) Interpersonal tie & 0.16 & 0.37 & & & & & & & & & & & & & \\
\hline (2) Vocabulary similarity & 0.57 & 0.22 & 0.16 & & & & & & & & & & & & \\
\hline (3) Same background & 0.74 & 0.44 & -0.04 & -0.03 & & & & & & & & & & & \\
\hline (4) Same gender & 0.70 & 0.46 & 0.03 & -0.06 & 0.11 & & & & & & & & & & \\
\hline (5) Same nationality & 0.51 & 0.50 & -0.05 & -0.03 & 0.02 & -0.04 & & & & & & & & & \\
\hline (6) Same previous subunit & 0.26 & 0.44 & 0.15 & 0.30 & -0.05 & -0.03 & -0.03 & & & & & & & & \\
\hline (7) Same role & 0.74 & 0.44 & 0.01 & -0.03 & -0.05 & -0.06 & 0.11 & 0.01 & & & & & & & \\
\hline (8) Same subunit & 0.19 & 0.39 & 0.29 & 0.39 & -0.03 & -0.02 & -0.03 & 0.45 & 0.01 & & & & & & \\
\hline (9) Tenure dissimilarity & 4.20 & 3.00 & 0.01 & -0.0002 & 0.05 & 0.12 & 0.04 & 0.04 & 0.11 & 0.03 & & & & & \\
\hline (10) Subunit identity & 4.96 & 1.44 & -0.02 & -0.05 & 0.04 & -0.10 & -0.03 & 0.001 & -0.01 & 0.03 & -0.04 & & & & \\
\hline (11) Organization identity & 5.35 & 1.68 & -0.01 & -0.07 & 0.17 & -0.05 & -0.01 & -0.11 & -0.03 & -0.03 & -0.01 & 0.45 & & & \\
\hline (12) Structural nonequivalence & 3.25 & 0.66 & -0.31 & 0.02 & -0.05 & -0.04 & -0.05 & -0.11 & -0.05 & -0.22 & -0.08 & -0.02 & -0.02 & & \\
\hline (13) Network size (log) & 2.04 & 0.49 & 0.14 & 0.12 & -0.12 & 0.10 & -0.05 & 0.01 & 0.02 & 0.02 & -0.004 & -0.13 & -0.09 & 0.40 & \\
\hline (14) Reciprocity & 0.16 & 0.37 & 0.45 & 0.21 & -0.04 & 0.02 & -0.06 & 0.18 & 0.02 & 0.36 & -0.0002 & -0.04 & -0.03 & -0.37 & 0.09 \\
\hline
\end{tabular}

Notes. Correlations $\geq|0.03|$ are significant at $p<0.05$. DV, dependent variable. 
Table 2. Linear Regression for the Influence of Interpersonal Ties on Vocabulary Similarity Change

\begin{tabular}{|c|c|c|c|c|c|}
\hline & $\begin{array}{l}\text { Model } 1 \text { coeff. } \\
\text { (S.E.) }\end{array}$ & $\begin{array}{l}\text { Model } 2 \text { coeff. } \\
\text { (S.E.) }\end{array}$ & $\begin{array}{l}\text { Model } 3 \text { coeff. } \\
\text { (S.E.) }\end{array}$ & $\begin{array}{l}\text { Model } 4 \text { coeff. } \\
\text { (S.E.) }\end{array}$ & $\begin{array}{l}\text { Model } 5 \text { coeff. } \\
\text { (S.E.) }\end{array}$ \\
\hline Vocabulary similarity & $\begin{array}{r}0.043^{*} \\
(0.025)\end{array}$ & $\begin{array}{c}0.038 \\
(0.026)\end{array}$ & $\begin{array}{l}0.065^{* * * *} \\
(0.024)\end{array}$ & $\begin{array}{l}0.086^{* * *} \\
(0.031)\end{array}$ & $\begin{array}{l}0.098^{* * *} \\
(0.030)\end{array}$ \\
\hline Same background & $\begin{array}{c}0.018 \\
(0.013)\end{array}$ & $\begin{array}{c}0.018 \\
(0.013)\end{array}$ & $\begin{array}{c}0.021 \\
(0.013)\end{array}$ & $\begin{array}{l}0.023^{* *} \\
(0.010)\end{array}$ & $\begin{array}{l}0.023^{* *} \\
(0.010)\end{array}$ \\
\hline Same gender & $\begin{array}{c}0.0003 \\
(0.008)\end{array}$ & $\begin{array}{c}0.0001 \\
(0.008)\end{array}$ & $\begin{array}{c}-0.002 \\
(0.007)\end{array}$ & $\begin{array}{c}-0.0005 \\
(0.009)\end{array}$ & $\begin{array}{c}0.0004 \\
(0.008)\end{array}$ \\
\hline Same nationality & $\begin{array}{c}-0.001 \\
(0.004)\end{array}$ & $\begin{array}{c}-0.002 \\
(0.004)\end{array}$ & $\begin{array}{c}-0.0001 \\
(0.004)\end{array}$ & $\begin{array}{c}0.002 \\
(0.004)\end{array}$ & $\begin{array}{c}0.002 \\
(0.004)\end{array}$ \\
\hline Same previous subunit & $\begin{array}{l}0.113^{* * *} \\
(0.017)\end{array}$ & $\begin{array}{l}0.113^{* * *} \\
(0.018)\end{array}$ & $\begin{array}{l}0.104^{* * *} \\
(0.017)\end{array}$ & $\begin{array}{l}0.060^{* * *} \\
(0.013)\end{array}$ & $\begin{array}{l}0.059^{* * *} \\
(0.013)\end{array}$ \\
\hline Same role & $\begin{array}{c}0.003 \\
(0.008)\end{array}$ & $\begin{array}{c}0.002 \\
(0.008)\end{array}$ & $\begin{array}{c}-0.001 \\
(0.008)\end{array}$ & $\begin{array}{c}0.007 \\
(0.009)\end{array}$ & $\begin{array}{c}0.008 \\
(0.009)\end{array}$ \\
\hline Tenure dissimilarity & $\begin{array}{l}0.002^{* *} \\
(0.001)\end{array}$ & $\begin{array}{l}0.003^{* * *} \\
(0.001)\end{array}$ & $\begin{array}{l}0.002^{* *} \\
(0.001)\end{array}$ & $\begin{array}{l}0.002^{* *} \\
(0.001)\end{array}$ & $\begin{array}{l}0.002^{* *} \\
(0.001)\end{array}$ \\
\hline Subunit identity & & $\begin{array}{c}-0.007 \\
(0.005)\end{array}$ & $\begin{array}{l}-0.006 \\
(0.005)\end{array}$ & $\begin{array}{c}-0.005 \\
(0.004)\end{array}$ & $\begin{array}{c}-0.005 \\
(0.004)\end{array}$ \\
\hline Organization identity & & $\begin{array}{c}0.004 \\
(0.006)\end{array}$ & $\begin{array}{c}0.004 \\
(0.006)\end{array}$ & $\begin{array}{c}0.003 \\
(0.005)\end{array}$ & $\begin{array}{c}0.003 \\
(0.005)\end{array}$ \\
\hline Structural nonequivalence & & & $\begin{array}{l}-0.020^{* *} \\
(0.009)\end{array}$ & $\begin{array}{c}0.013 \\
(0.009)\end{array}$ & $\begin{array}{c}0.012 \\
(0.009)\end{array}$ \\
\hline Network size (log) & & & $\begin{array}{c}0.001 \\
(0.002)\end{array}$ & $\begin{array}{r}0.0001 \\
(0.002)\end{array}$ & $\begin{array}{c}0.0001 \\
(0.002)\end{array}$ \\
\hline Reciprocity & & & $\begin{array}{l}0.047^{* * * *} \\
(0.012)\end{array}$ & $\begin{array}{c}0.005 \\
(0.012)\end{array}$ & $\begin{array}{c}0.002 \\
(0.012)\end{array}$ \\
\hline Same subunit & & & & $\begin{array}{l}0.160^{* * * *} \\
(0.027)\end{array}$ & $\begin{array}{l}0.133^{* * * *} \\
(0.031)\end{array}$ \\
\hline Interpersonal tie & & & & $\begin{array}{l}0.049^{* * *} \\
(0.017)\end{array}$ & $\begin{array}{c}0.006 \\
(0.011)\end{array}$ \\
\hline Interpersonal tie $\times$ Same subunit & & & & & $\begin{array}{l}0.107^{* * *} \\
(0.031)\end{array}$ \\
\hline Constant & $\begin{array}{c}-0.060 \\
(0.051)\end{array}$ & $\begin{array}{c}-0.057 \\
(0.052)\end{array}$ & $\begin{array}{c}0.003 \\
(0.062)\end{array}$ & $\begin{array}{c}-0.090 \\
(0.053)\end{array}$ & $\begin{array}{c}-0.069 \\
(0.051)\end{array}$ \\
\hline Person dummies & Included & Included & Included & Included & Included \\
\hline Period dummies & Included & Included & Included & Included & Included \\
\hline$n$ & 3,003 & 3,003 & 3,003 & 3,003 & 3,003 \\
\hline Adjusted $R^{2}$ & 0.41 & 0.41 & 0.42 & 0.48 & 0.49 \\
\hline$F$ & & 1.73 & $16.02^{* * *}$ & $24.75^{* * *}$ & $12.24^{* * *}$ \\
\hline
\end{tabular}

Notes. Robust standard errors clustered by respondent are in parentheses. Time-varying covariates were lagged by one period. The $F$-statistic is used to test the significance of the increase in explained variance as a result of the effect block added to each nested model. S.E., standard error. ${ }^{*} p<0.10 ;{ }^{* *} p<0.05 ;{ }^{* * *} p<0.01$.

explains significantly the increase in similarity of vocabularies adopted over time $(t$-test $=4.23, p<0.01)$. Interestingly, Figure 2 also shows that being in the same subunit has a higher effect on change in vocabulary similarity relative to being in different subunits. Consistent with our arguments (e.g., Krackhardt 1999), this seems to suggest that subunit membership entails processes of cultural alignment between members, which are made more salient and relevant by interpersonal communication (i.e., the marginal value of similarity change for organizational members linked by a communication tie is almost two times the marginal value for organizational members who are not linked by a communication tie). Is there any evidence of the alternative path-that is, the presence of a tie between managers across different subunits explaining the likelihood of increase in vocabulary similarity? This was not the case. As expected and shown in Figure 2, indeed, for managers who are affiliated to different subunits, the presence of a taskrelated communication tie does not increase significantly the similarity of vocabularies adopted over time $(t$-test $=0.60, p=0.55)$.

Table 3 presents the results of the logistic regression models investigating effects of vocabulary similarity at time $(t-1)$ on the likelihood that two managers form a communication tie in the following period $(t)$. Recall Hypothesis 2: between organizational subunits, the more two members share similar organizational vocabularies, the more they are likely to form 
Figure 2. Margins for the Influence of Interpersonal Ties on Vocabulary Similarity Change by Subunit Affiliation

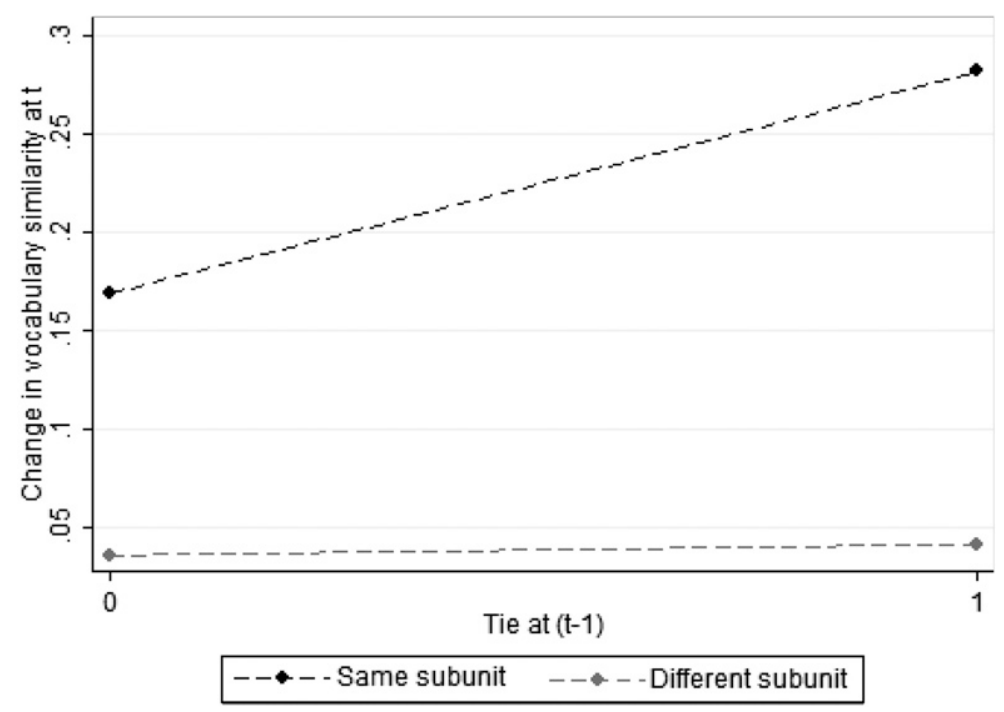

Notes. The margins are displayed in slope form for symmetry with Figure 3. Because Same subunit and Interpersonal tie are both dummy variables, we interpret the marginal values only.

a task-related communication tie over time. This hypothesis was supported. Model 5, which accounts for the main terms and all control effects, shows that the interaction of Vocabulary similarity and Different subunit is significantly positive $(\mathrm{B}=3.608, p<0.01)$; when including the interaction effect, the log-likelihood of the model is significantly smaller than for Model 4, in which controls and independent variables are introduced (as shown by the significant Wald $\chi^{2}$ test for change in the value of the log likelihood). Consistent with our prediction, just using similar organizational vocabulary does not explain the likelihood to form a tie with a coworker in the organizational network $(\mathrm{B}=$ $1.238, p=0.38$ ). Membership of different subunits makes resonant the effects of vocabulary similarity on the formation of communication ties.

To probe the interaction, we computed the margins at 1 SD below and 1 SD above the mean of Vocabulary similarity and plotted the predicted probabilities of forming a new tie corresponding to low and high values of vocabulary similarity by subunit affiliation, setting all other covariates to their mean values. As illustrated in Figure 3, as vocabulary similarity increases, new ties become more likely to be observed between than within subunits. A simple slope test-computed comparing the $y$-value at $(M-1 S D)$ and $(M+1 S D)$ of vocabulary similarity on each slope-showed that the predicted positive relationship between similarity in the vocabulary adopted and the probability to form a new tie between subunits was significant $\left(\chi^{2}=4.05\right.$, $p<0.01)$. Is there any evidence of vocabulary similarity influencing the likelihood to form a tie within subunits? This was not the case. The relationship between vocabulary similarity and probability to form a new tie was indeed nonsignificant for managers who were members of the same subunit. Specifically, the probability of forming a new tie within subunit boundaries did not change significantly across levels of vocabulary similarity $\left(\chi^{2}=-1.45, p=0.148\right)$.

Of note, the levels of identification of the managers with their subunit and with the organization (Subunit identity and Organization identity) did not affect the likelihood of developing new ties (e.g., Lomi et al. 2014). Again, our main results were not affected by other network features (Network size, Structural nonequivalence, and Reciprocity) that could potentially influence the relationship between vocabulary similarity and processes of interpersonal tie formation.

\section{Robustness Checks}

Time Effects. Our modelling approach posited that changes in organizational vocabularies and network structure observed at $(t)$ are a function of independent and control variables at $(t-1)$. Considering that our database includes observations collected at three different time points, are the same results confirmed while looking at changes at $(t)$ as a function of variables at $(t-2)$ ? To answer this question, we computed the dependent variables as change occurred between the beginning $(t-2)$ and the end $(t)$ of the observation period. We rerun the models including time-varying independent and control covariates at $(t-1)$ and $(t-2)$ as well as time-invariant control covariates. Interaction effects at both $(t-1)$ and $(t-2)$ were significant for both regression models, confirming our findings.

Split Sample. To compare directly network and vocabulary evolution within and across subunit boundaries, 
Table 3. Logistic Regression for the Influence of Vocabulary Similarity on Interpersonal Tie Formation

\begin{tabular}{|c|c|c|c|c|c|}
\hline & $\begin{array}{l}\text { Model } 1 \text { coeff. } \\
\text { (S.E.) }\end{array}$ & $\begin{array}{l}\text { Model } 2 \text { coeff. } \\
\text { (S.E.) }\end{array}$ & $\begin{array}{l}\text { Model } 3 \text { coeff. } \\
\text { (S.E.) }\end{array}$ & $\begin{array}{l}\text { Model } 4 \text { coeff. } \\
\text { (S.E.) }\end{array}$ & $\begin{array}{l}\text { Model } 5 \text { coeff. } \\
\text { (S.E.) }\end{array}$ \\
\hline Same background & $\begin{array}{c}0.123 \\
(0.196)\end{array}$ & $\begin{array}{c}0.124 \\
(0.109)\end{array}$ & $\begin{array}{c}0.114 \\
(0.186)\end{array}$ & $\begin{array}{c}0.102 \\
(0.207)\end{array}$ & $\begin{array}{c}0.106 \\
(0.212)\end{array}$ \\
\hline Same gender & $\begin{array}{c}0.370 \\
(0.261)\end{array}$ & $\begin{array}{c}0.360 \\
(0.260)\end{array}$ & $\begin{array}{c}0.354 \\
(0.263)\end{array}$ & $\begin{array}{c}0.406 \\
(0.254)\end{array}$ & $\begin{array}{r}0.425^{*} \\
(0.258)\end{array}$ \\
\hline Same nationality & $\begin{array}{c}0.146 \\
(0.173)\end{array}$ & $\begin{array}{c}0.164 \\
(0.184)\end{array}$ & $\begin{array}{c}0.143 \\
(0.187)\end{array}$ & $\begin{array}{c}0.135 \\
(0.185)\end{array}$ & $\begin{array}{c}0.119 \\
(0.180)\end{array}$ \\
\hline Same previous subunit & $\begin{array}{c}-0.162 \\
(0.252)\end{array}$ & $\begin{array}{c}-0.112 \\
(0.253)\end{array}$ & $\begin{array}{c}-0.118 \\
(0.259)\end{array}$ & $\begin{array}{c}-0.024 \\
(0.259)\end{array}$ & $\begin{array}{c}-0.070 \\
(0.250)\end{array}$ \\
\hline Same role & $\begin{array}{c}-1.066^{* *} \\
(0.524)\end{array}$ & $\begin{array}{l}-1.027^{* *} \\
(0.513)\end{array}$ & $\begin{array}{c}-1.107^{* *} \\
(0.532)\end{array}$ & $\begin{array}{c}-1.092^{* *} \\
(0.510)\end{array}$ & $\begin{array}{c}-1.093^{* *} \\
(0.506)\end{array}$ \\
\hline Tenure dissimilarity & $\begin{array}{c}-0.058 \\
(0.036)\end{array}$ & $\begin{array}{c}-0.047 \\
(0.037)\end{array}$ & $\begin{array}{c}-0.047 \\
(0.038)\end{array}$ & $\begin{array}{c}-0.051 \\
(0.037)\end{array}$ & $\begin{array}{c}-0.049 \\
(0.038)\end{array}$ \\
\hline Subunit identity & & $\begin{array}{c}0.104 \\
(0.112)\end{array}$ & $\begin{array}{c}0.137 \\
(0.114)\end{array}$ & $\begin{array}{c}0.111 \\
(0.112)\end{array}$ & $\begin{array}{c}0.103 \\
(0.112)\end{array}$ \\
\hline Organization identity & & $\begin{array}{c}-0.077 \\
(0.108)\end{array}$ & $\begin{array}{c}-0.085 \\
(0.108)\end{array}$ & $\begin{array}{c}-0.076 \\
(0.106)\end{array}$ & $\begin{array}{c}-0.069 \\
(0.105)\end{array}$ \\
\hline Structural nonequivalence & & & $\begin{array}{c}-0.482 \\
(0.313)\end{array}$ & $\begin{array}{c}-0.503 \\
(0.309)\end{array}$ & $\begin{array}{r}-0.502^{*} \\
(0.293)\end{array}$ \\
\hline Network size (log) & & & $\begin{array}{c}-0.475 \\
(0.328)\end{array}$ & $\begin{array}{c}-0.426 \\
(0.313)\end{array}$ & $\begin{array}{c}-0.444 \\
(0.315)\end{array}$ \\
\hline Reciprocity & & & $\begin{array}{c}-0.562 \\
(0.488)\end{array}$ & $\begin{array}{c}-0.665 \\
(0.544)\end{array}$ & $\begin{array}{c}-0.476 \\
(0.497)\end{array}$ \\
\hline Different subunit & & & & $\begin{array}{c}0.695 \\
(0.429)\end{array}$ & $\begin{array}{c}-1.378^{* *} \\
(0.678)\end{array}$ \\
\hline Vocabulary similarity & & & & $\begin{array}{l}3.652^{* * *} \\
(1.265)\end{array}$ & $\begin{array}{c}1.238 \\
(1.419)\end{array}$ \\
\hline $\begin{array}{l}\text { Vocabulary similarity } \times \text { Different } \\
\text { subunit }\end{array}$ & & & & & $\begin{array}{l}3.608^{* * *} \\
(1.344)\end{array}$ \\
\hline Constant & $\begin{array}{c}-1.136 \\
(1.109)\end{array}$ & $\begin{array}{c}-1.752 \\
(1.117)\end{array}$ & $\begin{array}{c}0.077 \\
(1.273)\end{array}$ & $\begin{array}{c}-2.475 \\
(1.642)\end{array}$ & $\begin{array}{c}-1.142 \\
(1.591)\end{array}$ \\
\hline Person dummies & Included & Included & Included & Included & Included \\
\hline Period dummies & Included & Included & Included & Included & Included \\
\hline$n$ & 3,003 & 3,003 & 3,003 & 3,003 & 3,003 \\
\hline Model log-likelihood & -441.15 & -440.75 & -437.52 & -427.66 & -423.85 \\
\hline Wald $\chi^{2}$ test & & 0.87 & 5.02 & $8.43^{* *}$ & $15.27^{* * *}$ \\
\hline
\end{tabular}

Notes. Robust standard errors clustered by respondent are in parentheses. Time-varying covariates were lagged by one period. The Wald $\chi^{2}$ statistic is used to test the significance of the increase in explained variance as a result of the effect block added to each nested model. S.E., standard error.

${ }^{*} p<0.10 ;{ }^{* *} p<0.05 ;{ }^{* * *} p<0.01$.

we split the sample (Kleinbaum et al. 2015) in two nonoverlapping subsamples including only either dyads of managers within subunits (604 observations) or dyads of managers between different subunits $(2,516$ observations). Then, we reran the models separately for pairs of managers who were members of the same subunit or of different subunits. The findings were confirmed.

\section{Controlling for Extradyadic Network Structures.} Extradyadic network structures can influence interaction patterns among organizational members (e.g., Lomi et al. 2014). This is the case of structural embeddedness whereby the presence of mutual contacts can facilitate interaction and development of similar vocabularies. The indicator of embeddedness that we used in the additional analysis is Burt's constraint (Burt 1992, pp. 54-56), which allowed us to measure low (i.e., brokerage) and high (i.e., closure) embeddedness as two opposites. Specifically, we used the square root transformation which eliminates bias to estimation and skewness (Kleinbaum 2017). To control for the possible effect of embeddedness on our main results, we reran the regression models adding Burt's constraint. The results were not significant, nor were our patterns of results modified.

To model directly the effects of more nuanced forms of embeddedness on the propensity to interact, we replicated the analysis conducting exponential random graph models (ERGMs), a network approach that controls for nonindependence of observations while testing the effects of dyadic and extradyadic 
Figure 3. Simple Slopes for the Probability of Forming a New Tie for Low and High Values of Vocabulary Similarity by Subunit Affiliation

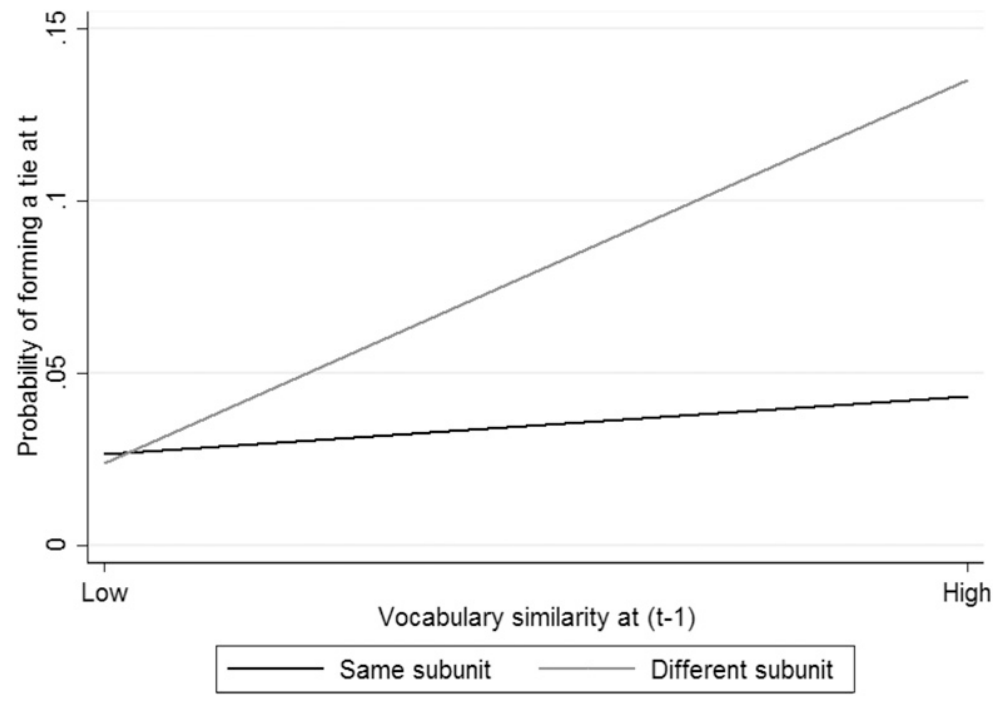

structures (Carnabuci and Diószegi 2015, Amati et al. 2018). Specifically, we estimated ERGMs testing the effects of theoretical interest while controlling for the influence of transitive closure (i.e., tendency toward transforming indirect contacts into direct ones), cyclic closure (i.e., tendency toward generalized reciprocity), and multiconnectivity (i.e., tendency toward brokering between pairs of disconnected others) on managers $i$ and $j$ being connected. Patterns of results remained confirmed.

Alternative Sources of Homophily. We tested alternative sources of homophily that could potentially affect patterns of tie formation and similarity in organizational vocabularies beyond formal affiliation to a subunit. Considering their organizational relevance, we focused on managers' hierarchical role (heads of a subunit, CFO, and $\mathrm{COO}$ or not) in the organization, on their similarity in tenure in the organization, and on their educational background (managerial or technical) (Tasselli 2015). We reestimated our models including, as alternative interaction factors, Same role $(t-1) \times$ Interpersonal tie $(t-1)$ and Same role $(t-1) \times$ Vocabulary similarity $(t-1)$. We replicated the analysis with Tenure dissimilarity and Same background. All interactions were nonsignificant, and results remained unchanged, ruling out the possibility of alternative sources of homophily explaining our findings.

Controlling for Possible High Status Recall Bias. Respondents can be more likely to recall contacts to high-status people than to peers (Krackhardt 1987). Is there any evidence of this bias in our sample? This was not the case. We checked for whether respondents were more likely to mention as personal contacts people higher in organizational rank (i.e., subunit heads, $\mathrm{CFO}$, and $\mathrm{COO}$ ) than their peers. Multiple $t$-tests showed that, on average, respondents did not recall, in percentage, more ties to high-status individuals than to other members of the organization. To further rule out the possibility that any eventual recall bias could affect our findings, we replicated the regression models, omitting managers high in organizational rank from the sample. Patterns of results remained unchanged.

\section{Subunit Effects on Vocabulary Homogeneity Across}

Boundaries. We also conducted additional analyses to test the possibility that an increase in similarity in vocabularies between different subunits might depend on idiosyncratic and often unobservable characteristics of the subunits (e.g., their activities or their internal culture) that make the vocabularies used by managers in the subunits relatively homogeneous. To check for this possibility, we reestimated the logistic regression models testing Hypothesis 2 including subunit fixed effects to control for unobserved heterogeneity at the subunit level. Results remained unchanged.

To investigate this insight further, we conducted two-way repeated measures analysis of variance (ANOVA) to detect whether managers assigned to each subunit were more or less likely, on average, to display higher levels of similarity in organizational vocabularies with members of specific different subunits. Of all possible combinations between managers, we found significant values of vocabulary similarity only between managers of subunits 3 (energy services) and 4 (mobility solutions). To confirm the robustness of our predictions, we reran logistic regression models on the subsample including only the 27 managers of the other subunits. Results remained unchanged. 
Subunit Effects on Vocabulary Similarity Change. Our regression analysis reveals that similarity in vocabularies tends to increase slightly over time also for members of the same subunit who are not connected by communication ties (on average, by 0.11 between adjacent periods). What are the potential reasons for this effect? To investigate the influence of unobserved idiosyncratic characteristics of the subunits on increases in vocabulary similarity, we conducted repeated measures ANOVA on the subsample of managers who were members of the same subunit but did not entertain a relationship at $(t-1)$. Results showed that the increase of similarity in vocabularies was significantly higher for subunits 4 and 5 only. To confirm the robustness of our findings, we split the sample and reran separate linear regression models on the managers of subunits $1-3$ and subunits $4-5$. Results remained unchanged, confirming the validity of our hypotheses.

Social Identity. Because social identity has been repeatedly defined as deeply intertwined with vocabulary development (e.g., Carley 1994), we conducted additional analyses to test the alternative possibilities that managers tend to form communication ties because of their similarity in organizational identities and that managers increase over time similarity in their level of organizational identity because they communicate with each other. The regression coefficients of these additional analyses were nonsignificant, ruling out these alternative explanations. (The results of all these robustness tests are not reported in the tables; they are available upon request.)

\section{Discussion}

But words are things, and a small drop of ink,

Falling like dew, upon a thought, produces

That which makes thousands, perhaps millions, think. -Lord Byron, Don Juan

Through a longitudinal study in a multiunit organization, we have found that communication patterns within and across organizational subunits are contingent on the structure of the informal ties between managers and on the similarity of vocabularies that managers use to describe their organization. We have shown that within subunit boundaries, the presence of a communication tie between two managers predicts their likelihood to develop similar vocabularies over time; between subunit boundaries, however, similarity in organizational vocabularies makes two managers more likely to communicate with each other over time. The results are robust to a number of validity challenges, including alternative explanations, alternative paths, different temporal configurations, split samples, different network models, different sources of homophily, effects of extradyadic structures, subunit effects on vocabulary change, and additional analyses testing the role of vocabulary homogeneity between subunits and of organizational identity.

From these results, we argue that the long-established insight that organizational boundaries tend to be relatively impermeable to crosscutting social interactions (e.g., March and Simon 1958) holds true only when taking a structural perspective and thus neglecting the vocabularies that organizational members adopt to construct and share meaningful interpretations of their organizations. Vocabularies, from the perspective suggested in this paper, help organizational members develop systems of meanings (White 2008) through which they facilitate coordination and communication patterns across organizational structure.

\section{Limitations and Future Research}

The empirical setting of this study contains idiosyncratic features limiting the generalization of the results. One of these features is network delineation. We have focused on communication ties between managers. We have collected network data through surveys and extracted organizational vocabularies from texts written by the managers. Future research could use data collected using other sources, including email exchanges among managers, to provide further investigation of the relations between networks and vocabularies (e.g., Kleinbaum et al. 2013).

Yet people in social settings interact not only through instrumental communication ties but in other ways as well (Lomi et al. 2014, p. 454). Other networks that have attracted the interest of organizational researchers include friendship networks (Tasselli and Kilduff 2018) and adversarial networks of dislike (Klein et al. 2004). Given the expressive nature of these networks, it would be of interest to investigate the organizational consequences of the interplay between expressive ties and the vocabularies that people use to describe their meaningful interactions with coworkers, and not only to describe the organization.

The focus of our analysis is dyadic-whether managers become more similar in vocabularies or form a tie. Yet vocabularies within formal organizational aggregates could already present elements of homogeneity to start with, including the managers' function, tasks, and experience (e.g., Tasselli 2015). On the basis of this preceding similarity, managers could form coalitions with other managers, within and between subunits, to influence decisions about organization's goals. Future research is needed to investigate whether and how common meanings embedded in vocabularies can provide a basis for identifying alignment in interests and so a basis for the formation and change of political coalitions in organizations (see Stevenson and Greenberg 2000). 
In examining the extent to which sharing vocabularies drives interpersonal communication between subunit boundaries, future work should better investigate where similarity of vocabularies across boundaries comes from. Robustness tests rule out the possibility that our theoretical arguments are contingent on vocabulary homogeneity between subunits and on homophily in relevant individual characteristics such as organizational background, tenure, and education. There is established evidence that psychological differences in variables such as personality and motivation can influence language acquisition and expression (e.g., Dörnyei 2014). Further research could therefore analyze whether patterns of vocabulary similarity and difference across formal boundaries depend on particular psychological traits of interacting organizational members.

\section{Practical Implications}

Organizations and managers aim at enabling coordination across functional and company boundaries as a way to enhance organizational performance. However, most of the solutions adopted by companies to foster boundary spanning are structural, including the planning of workflows or processes (Power 2012) and organizational redesign or change (Tasselli 2019). An alternative possibility, suggested in our research, is that cultural alignment boosts the extent to which people bridge structural boundaries within the organization. Rather than introducing structural change, which often fosters further misalignment between people and groups (e.g., Barley 1990), organizations might help employees and managers to develop a common understanding of the organization's core values and beliefs. And, as shown in our study, alignment in meanings can be realized by fostering informal, rather than formal, opportunities of interaction among organizational members (see Krackhardt and Hanson 1993). Organizations can thus "do things with words" (Lockwood et al. 2019, p. 8), leveraging cultural alignment as a powerful way to facilitate interunit coordination and compress organizational distance.

\section{Research Contributions}

The study of how social structure and vocabularies combine in explaining patterns of cross-boundary interaction and organizational functioning is of increasing interest to those seeking to investigate the role of meanings in organizational networks (see Groenewegen et al. 2017 and Ocasio et al. 2018 for recent examples). The study of vocabularies has been traditionally neglected by organizational network research, which often relied on the assumption that social structures and processes "vastly transcend the individual consciousness of actors" (Lorrain and White 1971, p. 50). Previous work mainly provided structural solutions to the issue of impermeability across intraorganizational boundaries (e.g., Reagans and McEvily 2003 and Tortoriello and Krackhardt 2010). Organizations, however, are distinctive social settings not only because they are defined by the presence of task-oriented patterns of interaction over time (e.g., March and Simon 1958). Their idiosyncratic nature, we argue, also derives from evidence that their formal structure (in terms, for example, of interconnected subunits) makes resonant patterns of similarity and difference in the meanings that organizational members attribute to the distinct layers of the organization itself. We provide conceptual and empirical evidence to the claim that "understanding actors' meanings[including vocabularies]-is crucial for any analysis of social structure" (Fine and Kleinman 1983, p. 106). A focus on the joint structure of social networks and vocabularies helps in better understanding the processes of organizational coordination in organizations. By incorporating vocabularies, therefore, we balance the structural emphasis of previous research on boundary spanning (Blau 1977).

We contribute to the growing but still scattered body of research on meaning, culture, and social networks (e.g., Mische 2003) by focusing on the intersection of vocabularies and networks as organized systems of meanings that people develop and share to bridge structural (Tasselli and Caimo 2019) and cultural (Pachucki and Breiger 2010) holes in organizations. Organizational analysis of structure and culture has "tended to treat these domains as discrete realms rather than together" (Pachucki and Breiger 2010, p. 206). We seize upon this need for integration by looking at organizational vocabulary as a catalyst bridging the cultural and structural domains of organizational coordination. In our view, research on organizational meaning and culture will benefit from a more systematic attention to the social structure of vocabularies; research on organizational social networks will benefit from a broader concern with issues of meaning carried, produced, and reproduced by network ties.

We hypothesized and showed that similarity in vocabularies between managers can be a source of homophily enabling boundary spanning. We also envisage prospects for further research on the role that heterophily in vocabulary plays in explaining coordination patterns in organizations. As one empirical investigation demonstrated, "The greater the heterogeneity the greater are the chances that any fortuitous encounter involves persons of different groups" (Blau et al. 1982, p. 47). Given the differentiation of work tasks between subunits, managers working in different subunits develop heterogeneous knowledge and abilities (Casciaro and Lobo 2008) that can lead them to develop different vocabularies 
describing the organization. In idiosyncratic contexts requiring knowledge and skill complementarity, such as functionally different groups or project teams, can variety, rather than overlap in vocabularies, explain the formation of cross-boundary ties?

Furthermore, we contribute to research integrating the analysis of formal and informal structure in organizations (see McEvily et al. 2014 for a recent review). With its emphasis on informal relationships between actors, social network research has progressively downplayed the fundamental role that formal organizational structure continues to play in processes of social interaction and identity formation (Hansen 2002). We build on recent insights (Kleinbaum et al. 2013) to argue that the "company behind the chart" (Krackhardt and Hanson 1993) interacts with the formal organizational chart in explaining social network ties within and across boundaries. We suggest that the patterns linking organizational vocabularies and social interactions are contingent on the formal, structural design of organizational subunits.

Building on this empirical study and on its contributions, we ask, can language be assigned with agency? We have reinterpreted language as a cognitive and cultural metacategory activating interpersonal connection beyond and across the boundaries of social and organizational distance. Vocabularies and networks, we suggest, cannot longer be treated as independent ontological realms, as research following anticategorical logics (e.g., Wellman 1988) seemed to claim. Nor can networks of words be simply conceived as semantic "systems" artificially separated from the daily social interactions of organizational members (see White 2008). Rather, we envisage prospects for considering social networks and organizational vocabularies as a phenomenological duality potentially subject to mutual coevolution (e.g., Tasselli et al. 2015). Behind the investigation of patterns of structural adjustment, future research is needed to analyze whether the meaning embedded in language and vocabularies plays a role in influencing and shaping the content itself, and therefore the consequences, of social interaction. If language affects tie formation, as we have tested in this study, can it also help predict network advantage and thus the authentic outcomes associated with networking behavior in organizations?

In conclusion, the message of this study is that organizational network structure combines with the structure of organizational vocabularies to affect the extent to which members communicate meaningfully within and across organizational boundaries. This study makes an important first step toward a better understanding of the role that vocabularies of organizing may play, as generators of meaning and relations, in closing the cultural holes that prevent knowledge sharing and coordination in organizations.

\section{Acknowledgments}

The authors express their sincere appreciation to William Ocasio for his excellent editorial guidance and to three anonymous reviewers for their helpful comments and suggestions. The authors thank also Steve Borgatti, Lauren C. Howe, Jochen Menges, Nicolas Bastardoz, Caterina Liberati, and Viviana Amati for their useful feedback or advice. The paper benefited from conference presentations at the "Networks of Meanings-Recent Research on Structure, Content and Meaning Networks" symposium at the 2018 Academy of Management Annual Meeting in Chicago, IL, and at the subtheme on "Multi-level Network Research: The Relationship between Intra- and Interorganizational Networks" at the European Group for Organizational Studies Colloquium 2018 in Tallinn, Estonia. The paper benefited from presentations and research talks given by the first author at the Rotterdam School of Management, Erasmus University; ETH Zurich; the University of Zurich; the Università della Svizzera italiana, Lugano; HEC Paris; and the University of Bologna and by the second author at the University of Manchester.

\section{Endnotes}

${ }^{1}$ We started the analysis from an initial list of 1,289 distinct words provided by the managers across the three periods corresponding to 1,099 words at time 1, 1,096 at time 2, and 1,014 words at time 3 . The result of filtering out noninformative words was selecting a list of 1,037 words, corresponding to 939 words at time 1, 936 at time 2, and 862 words at time 3 . Through the common semantic patterns procedure, we obtained a set of 536 words, corresponding to 448 words at time 1, 470 words at time 2, and 444 words at time 3 . From generalizing concepts that have a similar meaning, we obtained a list of 242 distinct words: 211 words from the first period, 238 from the second, and 221 from the third.

${ }^{2}$ Raw frequency data might be inaccurate. For instance, in our sample, the raw frequency counts of the word "energy_source" are, on average, very high. In the first data collection, the word "energy_source" appears with the same frequency (eight times) in two texts, but the length of the two texts is very different-93 and 171 words, respectively, indicating that the word characterizes the vocabulary of the first manager more than the vocabulary of the second one. If not addressed, these drawbacks of the raw frequency counts could lead to overestimate the importance of the word "energy_source" in our sample. We divided the raw frequency count of word $k$ by a count of the total number of words in a given text $i$ (TF). Then we multiplied the relative frequency by the logarithmically scaled inverse fraction of the texts containing the word (IDF). Put another way, $f_{i k}^{T F-I D F}=\frac{f_{i k}}{\sum_{k=1}^{i k} f_{i k}} \times \ln \frac{40}{n_{k}}, k=1, \ldots, m ; i=1, \ldots, n$; where $n_{k}$ is the number of texts containing word $k$.

${ }^{3}$ The distance between manager $i$ and $j$ is technically a $\chi^{2}$ distance but can be computed as a Euclidean distance when principal components are retained. Put another way, $d_{i j}=\sqrt{\sum_{k=1}^{m}\left(c_{i k}-c_{j k}\right)^{2}}$ where $c_{i k}$ are coordinates of manager $i, c_{j k}$ are coordinates of manager $j$, and $m=8$. From $d_{i j}$, we computed similarity as follows: $s_{i j}=1-\left(d_{i j} / \max d\right)$, where $d$ is the highest distance value between pairs of managers observed at time $(t)$.

\section{References}

Abbott A (1988) The System of Professions: An Essay on the Division of Expert Labor (University of Chicago Press, Chicago).

Abrahamson E, Hambrick DC (1997) Attentional homogeneity in industries: The effect of discretion. J. Organ. Behav. 18(S1):513-532. 
Aiken LS, West SG (1991) Multiple Regression: Testing and Interpreting Interactions (Sage, Thousand Oaks, CA).

Amati V, Lomi A, Mira A (2018) Social network modeling. Annual Rev. Statist. Appl. 5:343-369.

Argote L, Ingram P (2000) Knowledge transfer: A basis for competitive advantage in firms. Organ. Behav. Human Decision Processes 82(1):150-169.

Argote L, McEvily B, Reagans R (2003) Managing knowledge in organizations: An integrative framework and review of emerging themes. Management Sci. 49(4):571-582.

Ashforth BE, Rogers KM, Corley KG (2011) Identity in organizations: Exploring cross-level dynamics. Organ. Sci. 22(5):1144-1156.

Balogun J, Johnson G (2004) Organizational restructuring and middle manager sensemaking. Acad. Management J. 47(4):523-549.

Barley SR (1990) The alignment of technology and structure through roles and networks. Admin. Sci. Quart. 35(1):61-103.

Basov N (2019) The ambivalence of cultural homophily: Field positions, semantic similarities, and social network ties in creative collectives. Poetics, ePub ahead of print May 2, https://doi.org/ $10.1016 /$ j.poetic.2019.02.004.

Bechky BA (2003) Sharing meaning across occupational communities: The transformation of understanding on a production floor. Organ. Sci. 14(3):312-330.

Bergami M, Bagozzi RP (2000) Self-categorization, affective commitment and group self-esteem as distinct aspects of social identity in the organization. British J. Soc. Psych. 39(4):555-577.

Berger PL, Luckmann T (1966) The Social Construction of Reality: A Treatise in the Sociology of Knowledge (Doubleday, New York).

Blau PM (1977) Inequality and Heterogeneity: A Primitive Theory of Social Structure (Free Press, New York).

Blau PM, Blum TC, Schwartz JE (1982) Heterogeneity and intermarriage. Amer. Sociol. Rev. 47(1):45-62.

Bowerman M, Choi S (2001) Shaping meanings for language: Universal and language-specific in the acquisition of spatial semantic categories. Bowerman M, Levinson SC, eds. Language Acquisition and Conceptual Development, Vol. 3 (Cambridge University Press, Cambridge, UK), 475-511.

Brass DJ, Galaskiewicz J, Greve HR, Tsai W (2004) Taking stock of networks and organizations: A multilevel perspective. Acad. Management J. 47(6):795-817.

Breiger RL (1974) The duality of persons and groups. Soc. Forces 53(2):181-190.

Breiger RL (2000) A tool kit for practice theory. Poetics 27(2-3):91-115.

Breiger RL, Mohr JW (2004) Institutional logics from the aggregation of organizational networks: Operational procedures for the analysis of counted data. Comput. Math. Organ. Theory 10(1): $17-43$.

Burt RS (1987) Social contagion and innovation: Cohesion vs. structural equivalence. Amer. J. Sociol. 92(6):1287-1335.

Burt RS (1992) Structural Holes (Harvard University Press, Cambridge, MA).

Burt RS (2008) Information and structural holes: comment on Reagans and Zuckerman. Indust. Corporate Change 17(5):953-969.

Burt RS, Merluzzi J (2016) Network oscillation. Acad. Management Discoveries 2(4):368-391.

Burt RS, Kilduff M, Tasselli S (2013) Social network analysis: Foundations and frontiers on advantage. Annual Rev. Psych. 64: $527-547$.

Caimo A, Lomi A (2015) Knowledge sharing in organizations: A Bayesian analysis of the role of reciprocity and formal structure. J. Management 41(2):655-691.

Carley KM (1986) An approach for relating social structure to cognitive structure. J. Math. Sociol. 12(2):137-189.

Carley KM (1994) Extracting culture through textual analysis. Poetics 22(4):291-312.

Carley KM (1997) Extracting team mental models through textual analysis. J. Organizational Behav. 18(S1):533-558.
Carley KM, Columbus D, Azoulay A (2012) Automap user's guide 2012. Report CMU-ISR-12-106, Carnegie Mellon University, Pittsburgh.

Carnabuci G, Diószegi B (2015) Social networks, cognitive style, and innovative performance: A contingency perspective. Acad. Management J. 58(3):881-905.

Casciaro T, Lobo MS (2008) When competence is irrelevant: The role of interpersonal affect in task-related ties. Admin. Sci. Quart. 53(4):655-684.

Casciaro T, Lobo MS (2014) Affective primacy in intraorganizational task networks. Organ. Sci. 26(2):373-389.

Chua RY (2018) Innovating at cultural crossroads: How multicultural social networks promote idea flow and creativity. J. Management 44(3):1119-1146.

Collins J (2003) Cultural diversity and entrepreneurship: Policy responses to immigrant entrepreneurs in Australia. Entrepreneurship Regional Development 15(2):137-149.

Cramton CD (2001) The mutual knowledge problem and its consequences for dispersed collaboration. Organ. Sci. 12(3):346-371.

Crilly D, Sloan P (2014) Autonomy or control? Organizational architecture and corporate attention to stakeholders. Organ. Sci. 25(2):339-355.

Demetry D (2017) Pop-up to professional: Emerging entrepreneurial identity and evolving vocabularies of motive. Acad. Management Discoveries 3(2):187-207.

Dokko G, Kane AA, Tortoriello M (2014) One of us or one of my friends: How social identity and tie strength shape the creative generativity of boundary-spanning ties. Organ. Stud. 35(5): 703-726.

Dörnyei Z (2014) The Psychology of the Language Learner: Individual Differences in Second Language Acquisition (Routledge, New York).

Duncan OD, Haller AO, Portes A (1968) Peer influences on aspirations: A reinterpretation. Amer. J. Sociol. 74(2):119-137.

Dunn MB, Jones C (2010) Institutional logics and institutional pluralism: The contestation of care and science logics in medical education, 1967-2005. Admin. Sci. Quart. 55(1):114-149.

Fine GA, Kleinman S (1983) Network and meaning: An interactionist approach to structure. Symbolic Interaction 6(1):97-110.

Gartner WB (1993) Words lead to deeds: Toward an organizational emergence vocabulary. J. Bus. Venturing 8(3):231-239.

Gentner D, Goldin-Meadow S, eds. (2003) Language in Mind: Advances in the Study of Language and Thought (MIT Press, Cambridge, MA).

Greenacre M, Blasius J (1994) Correspondence Analysis in the Social Sciences: Recent Developments and Applications (Academic Press, London).

Groenewegen P, Ferguson JE, Moser C, Mohr JW, Borgatti SP, eds. (2017) Structure, Content and Meaning of Organizational Networks: Extending Network Thinking (Emerald Publishing, Bingley, UK).

Gulati R, Puranam P (2009) Renewal through reorganization: The value of inconsistencies between formal and informal organization. Organ. Sci. 20(2):422-440.

Hansen MT (2002) Knowledge networks: Explaining effective knowledge sharing in multiunit companies. Organ. Sci. 13(3):232-248.

Hinds PJ, Carley KM, Krackhardt D, Wholey D (2000) Choosing work group members: Balancing similarity, competence, and familiarity. Organ. Behav. Human Decision Processes 81(2):226-251.

Hirsch P (1986) From ambushes to golden parachutes: Corporate takeovers as an instance of cultural framing and institutional integration. Amer. J. Sociol. 91(4):800-837.

Homans GC (1950) The Human Group (Harper \& Row, New York).

Ibarra H (1999) Provisional selves: Experimenting with image and identity in professional adaptation. Admin. Sci. Quart. 44(4): 764-791.

Ibarra H, Andrews SB (1993) Power, social influence, and sense making: Effects of network centrality and proximity on employee perceptions. Admin. Sci. Quart. 38(2):277-303. 
Jones C, Livne-Tarandach R (2008) Designing a frame: Rhetorical strategies of architects. J. Organ. Behav. 29(8):1075-1099.

Jones C, Maoret M, Massa FG, Svejenova S (2012) Rebels with a cause: Formation, contestation, and expansion of the de novo category "modern architecture," 1870-1975. Organ. Sci. 23(6):1523-1545.

Khaire M (2010) Young and no money? Never mind: The material impact of social resources on new venture growth. Organ. Sci. 21(1):168-185.

Kilduff M, Tsai W, Hanke R (2006) A paradigm too far? A dynamic stability reconsideration of the social network research program. Acad. Management Rev. 31(4):1031-1048.

Kirchner C, Mohr JW (2010) Meanings and relations: An introduction to the study of language, discourse and networks. Poetics $38(6)$ : 555-566.

Klein KJ, Lim BC, Saltz JL, Mayer DM (2004) How do they get there? An examination of the antecedents of centrality in team networks. Acad. Management J. 47(6):952-963.

Kleinbaum AM (2017) Reorganization and tie decay choices. Management Sci. 64(5):2219-2237.

Kleinbaum AM, Jordan AH, Audia PG (2015) An altercentric perspective on the origins of brokerage in social networks: How perceived empathy moderates the self-monitoring effect. Organ. Sci. 26(4):1226-1242.

Kleinbaum AM, Stuart TE, Tushman ML (2013) Discretion within constraint: Homophily and structure in a formal organization. Organ. Sci. 24(5):1316-1336.

Kovacs B, Kleinbaum AM (2019) Language style similarity and friendship networks. Tuck School of Business Working Paper 3131715, Dartmouth University, Hanover, NH.

Krackhardt D (1987) Cognitive social structures. Soc. Networks 9(2): 109-134.

Krackhardt D (1998) Simmelian tie: Super strong and sticky. Kramer $\mathrm{R}$, Neale M, eds. Power and Influence in Organizations (Sage, Thousand Oaks, CA), 21-38.

Krackhardt D (1999) The ties that torture: Simmelian tie analysis in organizations. Res. Sociol. Organ. 16(1):183-210.

Krackhardt D, Hanson JR (1993) Informal networks: The company behind the chart. Harvard Bus. Rev. 71(4):104-113.

Krippendorff K (2004) Reliability in content analysis: Some common misconceptions and recommendations. Human Comm. Res. 30(3):411-433.

Lockwood C, Giorgi S, Glynn MA (2019) "How to do things with words": Mechanisms bridging language and action in management research. J. Management 45(1):7-34.

Loewenstein J (2014) Take my word for it: How professional vocabularies foster organizing. J. Professions Organ. 1(1):65-83.

Loewenstein J, Ocasio WC (2005) Vocabularies of organizing: How language links culture, cognition, and action in organizations. McCombs Working Paper OSSM-03-05, University of Texas at Austin, Austin.

Loewenstein J, Ocasio W, Jones C (2012) Vocabularies and vocabulary structure: A new approach linking categories, practices, and institutions. Acad. Management Ann. 6(1):41-86.

Lomi A, Tasselli S, Zappa P (2017) The network structure of organizational vocabularies. Groenewegen P, Ferguson JE, Moser C, Mohr JW, Borgatti SP, eds. Structure, Content and Meaning of Organizational Networks: Extending Network Thinking (Emerald Publishing, Bingley, UK), 65-85.

Lomi A, Lusher D, Pattison PE, Robins G (2014) The focused organization of advice relations: A study in boundary crossing. Organ. Sci. 25(2):438-457.

Lorrain F, White HC (1971) Structural equivalence of individuals in social networks. J. Math. Sociol. 1(1):49-80.

Maitlis S, Christianson M (2014) Sensemaking in organizations: Taking stock and moving forward. Acad. Management Ann. 8(1):57-125.
March JG, Simon HA (1958) Organizations (John Wiley \& Sons, Oxford, UK).

Marsden PV (1988) Homogeneity in confiding relations. Soc. Networks 10(1):57-76.

McEvily B, Soda G, Tortoriello M (2014) More formally: Rediscovering the missing link between formal organization and informal social structure. Acad. Management Ann. 8(1):299-345.

McPherson M, Smith-Lovin LM, Cook J (2001) Birds of a feather: Homophily in social networks. Annual Rev. Sociol. 27:415-444.

Mehra A, Kilduff M, Brass DJ (2001) The social networks of high and low self-monitors: Implications for workplace performance. Admin. Sci. Quart. 46(1):121-146.

Meyer RE, Höllerer MA (2010) Meaning structures in a contested issue field: A topographic map of shareholder value in Austria. Acad. Management J. 53(6):1241-1262.

Mills CW (1939) Language, logic, and culture. Amer. Sociol. Rev. 4(5): 670-680.

Mills CW (1940) Situated actions and vocabularies of motives. Amer. Sociol. Rev. 5(6):904-913.

Mische A (2003) Cross-talk in movements: rethinking the culturenetwork link. Diani M, McAdam D, eds. Social Movements and Networks: Relational Approaches to Collective Action (Oxford University Press, New York), 258-280.

Mizruchi MS, Koenig T (1988) Economic concentration and corporate political behavior: A cross-industry comparison. Soc. Sci. Res. 17(4):287-305.

Mohr JW, Wagner-Pacifici R, Breiger RL, Bogdanov P (2013) Graphing the grammar of motives in National Security Strategies: Cultural interpretation, automated text analysis and the drama of global politics. Poetics 41(6):670-700.

Morrison EW (2002) Newcomers' relationships: The role of social network ties during socialization. Acad. Management J. 45(6): 1149-1160.

Nag R, Hambrick DC, Chen MJ (2007) What is strategic management, really? Inductive derivation of a consensus definition of the field. Strategic Management J. 28(9):935-955.

Oberg A, Korff VP, Powell WW (2017) Culture and connectivity intertwined: Visualizing organizational fields as relational structures and meaning system. Groenewegen P, Ferguson JE, Moser C, Mohr JW, Borgatti SP, eds. Structure, Content and Meaning of Organizational Networks: Extending Network Thinking (Emerald Publishing, Bingley, UK), 17-48.

Ocasio W, Joseph J (2005) Cultural adaptation and institutional change: The evolution of vocabularies of corporate governance, 1972-2003. Poetics 33(3):163-178.

Ocasio W, Laamanen T, Vaara E (2018) Communication and attention dynamics: An attention-based view of strategic change. Strategic Management J. 39(1):155-167.

Ocasio W, Loewenstein J, Nigam A (2015) How streams of communication reproduce and change institutional logics: The role of categories. Acad. Management Rev. 40(1):28-48.

O'Reilly CA III, Caldwell DF, Barnett WP (1989) Work group demography, social integration, and turnover. Admin. Sci. Quart. 34(1):21-37.

Pachucki MA, Breiger RL (2010) Cultural holes: Beyond relationality in social networks and culture. Annual Rev. Sociol. 36:205-224.

Painter M, Pouryousefi S, Hibbert S, Russon JA (2019) Sharing vocabularies: Toward horizontal alignment of values-driven business functions. J. Bus. Ethics 155(4):965-979.

Pettigrew AM (1979) On studying organizational cultures. Admin Sci. Quart. 24(4):570-581.

Power B (2012) Get your team to work across organizational boundaries. Harvard Bus. Rev. (April 9), https://hbr.org/2012/ 04/building-a-team-across-organiz.

Reagans R (2011) Close encounters: Analyzing how social similarity and propinquity contribute to strong network connections. Organ. Sci. 22(4):835-849. 
Reagans R, McEvily B (2003) Network structure and knowledge transfer: The effects of cohesion and range. Admin. Sci. Quart. 48(2):240-267.

Ryan L (2016) Looking for weak ties: Using a mixed methods approach to capture elusive connections. Sociol. Rev. 64(4):951-969.

Sasovova Z, Mehra A, Borgatti SP, Schippers MC (2010) Network churn: The effects of self-monitoring personality on brokerage dynamics. Admin. Sci. Quart. 55(4):639-670.

Sherif M (1958) Superordinate goals in the reduction of intergroup conflict. Amer. J. Sociol. 63(4):349-356.

Shi W, Zhang Y, Hoskisson RE (2019) Examination of CEO-CFO social interaction through language style matching: Outcomes for the CFO and the organization. Acad. Management J. 62(2):383-414.

Simmel G (1971) On Individuality and Social Forms (University of Chicago Press, Chicago).

Simon HA (1947) Administrative Behaviour (Macmillan, New York).

Sonenshein S, Dholakia U (2012) Explaining employee engagement with strategic change implementation: A meaning-making approach. Organ. Sci. 23(1):1-23.

Srivastava SB, Banaji MR (2011) Culture, cognition, and collaborative networks in organizations. Amer. Sociol. Rev. 76(2):207-233.

Stevenson WB, Greenberg D (2000) Agency and social networks: Strategies of action in a social structure of position, opposition, and opportunity. Admin. Sci. Quart. 45(4):651-678.

Strong P, Robinson J (1990) The NHS Under New Management (Open University Press, Buckingham, UK).

Tajfel H (1972) La catégorisation sociale. Moscovici S, ed. Introduction à la psychologie sociale (Larousse, Paris), 272-302.

Tasselli S (2015) Social networks and inter-professional knowledge transfer: the case of healthcare professionals. Organ. Stud. 36(7):841-872.

Tasselli S (2019) At the end of an era: A model and three tales of memory, perception and reality. Acad. Management Rev. 44(3):701-717.

Tasselli S, Caimo A (2019) Does it take three to dance the Tango? Organizational design, triadic structures and boundary spanning across subunits. Soc. Networks 59(October):10-22.

Tasselli S, Kilduff M (2018) When brokerage between friendship cliques endangers trust: a personality-network fit perspective. Acad. Management J. 61(3):802-825.

Tasselli S, Kilduff M, Menges JI (2015) The microfoundations of organizational social networks: A review and an agenda for future research. J. Management 41(5):1361-1387.

Thompson EP (1967) Time, work-discipline, and industrial capitalism. Past Present 38(December):56-97.

Tortoriello M, Krackhardt D (2010) Activating cross-boundary knowledge: The role of Simmelian ties in the generation of innovations. Acad. Management J. 53(1):167-181.

Tortoriello M, McEvily B, Krackhardt D (2014) Being a catalyst of innovation: The role of knowledge diversity and network closure. Organ. Sci. 26(2):423-438.

Tortoriello M, Reagans R, McEvily B (2012) Bridging the knowledge gap: The influence of strong ties, network cohesion and network range on the transfer of knowledge between organizational units. Organ. Sci. 23(4):1024-1039.

Travers J, Milgram S (1967) The small world problem. Psych. Today 1(1):61-67.

Tsai W (2002) Social structure of "coopetition" within a multiunit organization: Coordination, competition, and intraorganizational knowledge sharing. Organ. Sci. 13(2):179-190.

Tushman ML, Nadler DA (1978) Information processing as an integrating concept in organizational design. Acad. Management Rev. 3(3):613-624.

Uzzi B (1999) Embeddedness in the making of financial capital: How social relations and networks benefit firms seeking financing. Amer. Sociol. Rev. 64(4):481-505.

Vaara E, Sonenshein S, Boje D (2016) Narratives as sources of stability and change in organizations: Approaches and directions for future research. Acad. Management Ann. 10(1):495-560.

Wasserman S, Faust K (1994) Social Network Analysis: Methods and Applications, Vol. 8 (Cambridge University Press, Cambridge, UK).

Watts G (1999) Small Worlds (Princeton University Press, Princeton, NJ)

Weber RP (1990) Basic Content Analysis, 2nd ed. (Sage, Thousand Oaks, CA).

Weick KE, Sutcliffe KM, Obstfeld D (2005) Organizing and the process of sensemaking. Organ. Sci. 16(4):409-421.

Wellman B (1988) Structural analysis: From method and metaphor to theory and substance. Wellman B, Berkowitz SD, eds. Social Structures: A Network Approach (Cambridge University Press, Cambridge, UK), 19-61.

White HC (2008) Identity and Control: How Social Formations Emerge (Princeton University Press, Princeton, NJ).

Wooldridge JM (2009) Introductory Econometrics: A Modern Approach 4th ed. (South-Western, Mason, $\mathrm{OH}$ ).

Stefano Tasselli is an associate professor at the Rotterdam School of Management, Erasmus University. He received his PhD from the University of Cambridge. His research interests include the microfoundations of organizational social networks, as well as organizational theory. Specifically, his research focuses on the interplay between characteristics of individual actors and network structure in explaining outcomes of importance for individuals and organizations.

Paola Zappa is an assistant professor at Maynooth University. Her current research examines the interplay of formal structures and informal social networks in organizations.

Alessandro Lomi is a professor at the University of Italian Switzerland, Lugano, and a distinguished research professor at the Exeter Business School. His interests include statistical models for the analysis of social networks within and between organizations. 